\title{
Triple-wavelength depolarization-ratio profiling of Saharan dust over Barbados during SALTRACE in 2013 and 2014
}

\author{
Moritz Haarig $^{1}$, Albert Ansmann ${ }^{1}$, Dietrich Althausen ${ }^{1}$, André Klepel ${ }^{1,2}$, Silke Groß ${ }^{3}$, Volker Freudenthaler ${ }^{4}$, \\ Carlos Toledano $^{5}$, Rodanthi-Elisavet Mamouri ${ }^{6}$, David A. Farrell ${ }^{7}$, Damien A. Prescod ${ }^{7}$, Eleni Marinou ${ }^{8}$, \\ Sharon P. Burton ${ }^{9}$, Josef Gasteiger ${ }^{10}$, Ronny Engelmann ${ }^{1}$, and Holger Baars ${ }^{1}$ \\ ${ }^{1}$ Leibniz Institute for Tropospheric Research, Leipzig, Germany \\ ${ }^{2}$ Technology Innovation Center, Goldschmidt Thermit GmbH, Leipzig, Germany \\ ${ }^{3}$ German Aerospace Center, Institute of Atmospheric Physics, Oberpfaffenhofen, Germany \\ ${ }^{4}$ Meteorological Institute, Ludwig Maximilians University, Munich, Germany \\ ${ }^{5}$ Group of Atmospheric Optics, University of Valladolid, Valladolid, Spain \\ ${ }^{6}$ Department of Civil Engineering and Geomatics, Cyprus University of Technology, Limassol, Cyprus \\ ${ }^{7}$ Caribbean Institute for Meteorology and Hydrology, Bridgetown, Barbados \\ ${ }^{8}$ Inst. for Astronomy, Astrophysics, Space Appl. and Remote Sensing, National Observatory Athens, Athens, Greece \\ ${ }^{9}$ NASA Langley Research Center, MS 475, Hampton, VA 23681, USA \\ ${ }^{10}$ Aerosol Physics and Environmental Physics, University of Vienna, Vienna, Austria
}

Correspondence to: Moritz Haarig (haarig@tropos.de)

Received: 24 February 2017 - Discussion started: 3 March 2017

Revised: 24 July 2017 - Accepted: 28 July 2017 - Published: 13 September 2017

\begin{abstract}
Triple-wavelength polarization lidar measurements in Saharan dust layers were performed at Barbados $\left(13.1^{\circ} \mathrm{N}, 59.6^{\circ} \mathrm{W}\right), 5000-8000 \mathrm{~km}$ west of the Saharan dust sources, in the framework of the Saharan Aerosol Longrange Transport and Aerosol-Cloud-Interaction Experiment (SALTRACE-1, June-July 2013, SALTRACE-3, June-July 2014). Three case studies are discussed. High quality was achieved by comparing the dust linear depolarization ratio profiles measured at 355,532 , and $1064 \mathrm{~nm}$ with respective dual-wavelength $(355,532 \mathrm{~nm})$ depolarization ratio profiles measured with a reference lidar. A unique case of long-range transported dust over more than $12000 \mathrm{~km}$ is presented. Saharan dust plumes crossing Barbados were measured with an airborne triple-wavelength polarization lidar over Missouri in the midwestern United States 7 days later. Similar dust optical properties and depolarization features were observed over both sites indicating almost unchanged dust properties within this 1 week of travel from the Caribbean to the United States. The main results of the triple-wavelength polarization lidar observations in the Caribbean in the summer seasons of 2013 and 2014 are summarized. On average, the particle linear depolarization ratios for aged Saharan dust were found to
\end{abstract}

be $0.252 \pm 0.030$ at $355 \mathrm{~nm}, 0.280 \pm 0.020$ at $532 \mathrm{~nm}$, and $0.225 \pm 0.022$ at $1064 \mathrm{~nm}$ after approximately 1 week of transport over the tropical Atlantic. Based on published simulation studies we present an attempt to explain the spectral features of the depolarization ratio of irregularly shaped mineral dust particles, and conclude that most of the irregularly shaped coarse-mode dust particles (particles with diameters $>1 \mu \mathrm{m}$ ) have sizes around 1.5-2 $\mu \mathrm{m}$. The SALTRACE results are also set into the context of the SAMUM-1 (Morocco, 2006) and SAMUM-2 (Cabo Verde, 2008) depolarization ratio studies. Again, only minor changes in the dust depolarization characteristics were observed on the way from the Saharan dust sources towards the Caribbean.

\section{Introduction}

Mineral dust belongs to the major natural atmospheric aerosol components and influences weather and climate, visibility, air quality, and human health. Large efforts are undertaken to develop sophisticated dust transport models to provide predictions of dust occurrence, vertical distribu- 
tion of dust particles and their impact on the Earth's radiation field, cloud formation, and environmental conditions (Huneeus et al., 2011; Heinold et al., 2011; Garimella et al., 2014; Solomos et al., 2017). A variety of features of the impact of dust on (climate-relevant) atmospheric processes are not well understood or represented in atmospheric models, and thus need to be explored, preferably in comprehensive field campaigns such as Aerosol Characterization Experiment ACE-Asia (Huebert et al., 2003; Shimizu et al., 2004), the Puerto Rico Dust Experiment PRIDE (Colarco et al., 2003; Reid et al., 2003), the Saharan Dust Experiment SHADE (Tanré et al., 2003), the Saharan Mineral Dust Experiments SAMUM-1 (Heintzenberg, 2009) and SAMUM-2 (Ansmann et al., 2011), the Dust and Biomass-burning Experiment DABEX (Haywood et al., 2008), the Dust Outflow and Deposition to the Ocean project DODO (McConnell et al., 2008), the Geostationary Earth Radiation Budget Intercomparisons of Long-wave and Short-wave radiation GERBILS (Johnson and Osborne, 2011), Fennec (Ryder et al., 2013), the Saharan Aerosol Long-Range Transport and Aerosol-Cloud-Interaction Experiment SALTRACE (Weinzierl et al., 2017), and the Study of Saharan Dust Over West Africa SHADOW (Veselovskii et al., 2016).

Besides a precise description of dust in atmospheric models, there is also a strong need for a better knowledge of the link between the microphysical and optical dust properties to improve dust profiling and retrieval techniques (Veselovskii et al., 2010, 2016; Müller et al., 2013; Lopatin et al., 2013; Chaikovsky et al., 2016; Bovchaliuk et al., 2016). Recently, a new aerosol retrieval technique was proposed, which makes use of depolarization-ratio profiling and permits the separation of fine dust, coarse dust, and residual (marine or anthropogenic) aerosol profiles in terms of light backscatter, extinction, and mass concentration (Mamouri and Ansmann, 2014). Based on SALTRACE triple-wavelength polarization measurements, an investigation is made into which of the three wavelengths this new method works best with and results in the lowest uncertainties (Mamouri and Ansmann, 2017).

One of the fundamental open questions regarding the influence of mineral dust on climate is related to the specific impact of the size, shape, and chemical composition characteristics of desert dust particles on light scattering and depolarization (Dubovik et al., 2006; Wiegner et al., 2009; Müller et al., 2010a, b, 2012; Gasteiger et al., 2011; Kemppinen et al., 2015a, b). Besides modeling studies and field observations, laboratory experiments contribute to this field of research (West et al., 1997; Volten et al., 2001; Liu et al., 2003; Curtis et al., 2008), with a focus also, recently, on lidar applications (Sakai et al., 2010; David et al., 2013; Miffre et al., 2016; Järvinen et al., 2016). Although significant progress has been made during the last decade, models describing the scattering properties of desert dust particles from forward scattering to backward scattering (up to angles of exactly $180^{\circ}$ ) need a number of assumptions, espe- cially about the particle morphology and composition when explaining the optical effects gained from active and passive remote sensing at different wavelengths from the UV to IR (Gasteiger et al., 2011; Kemppinen et al., 2015a, b). Observations of dust optical properties are in strong contradiction with model simulations when a spherical dust particle shape model is applied. The widely used and accepted approach to describe dust particles as spheroids works well in the case of sun photometer retrievals (Dubovik et al., 2006). However, significant uncertainties in the observational products arise whenever lidar measurements (and thus $180^{\circ}$ scattering processes) come into play and are included in the data analysis in which a spheroidal shape model is used (Wagner et al., 2013; Veselovskii et al., 2010, 2016; Müller et al., 2013). There is a clear need for complex efforts of simulation studies, laboratory investigations, and field observations in order to better parametrize the relationship between the dust particle shape and size distribution characteristics and the scattering phase function, with emphasis on depolarization and scattering at high scattering angles. The depolarization ratio observed with lidar is rather sensitive to the dust particle shape (Gasteiger et al., 2011; Kemppinen et al., 2015a). The spectral dependence of depolarization, as presented in this article, also contains information on the dust size spectrum. Thus, triple-wavelength depolarization-ratio observations are of great value for the optical modeling community (Gasteiger and Freudenthaler, 2014) and support efforts to develop realistic dust shape models, which are not available yet. In the first stage, however, we have to demonstrate that triplewavelength depolarization observations can be successfully performed.

To contribute to this field of dust research, we redesigned and upgraded our multiwavelength polarization/Raman lidar BERTHA (Backscatter Extinction lidar-Ratio Temperature Humidity profiling Apparatus; Althausen et al., 2000; Tesche et al., 2009; Haarig et al., 2016b). BERTHA has been used in nine field campaigns in Europe, Asia, and Africa from 1997 to 2008 (Wandinger et al., 2002; Ansmann et al., 2002; Franke et al., 2003; Tesche et al., 2009, 2011a). We implemented new channels to permit simultaneous observations of dust linear depolarization ratios at 355 , 532, and $1064 \mathrm{~nm}$. Freudenthaler et al. (2009) and Burton et al. (2015) showed already that the dust linear depolarization ratio significantly changes with the transmitted laser wavelength, obviously as a result of changing contributions of fine-mode dust particles (particles with diameters $<1 \mu \mathrm{m}$ ) and coarse-mode (super-micrometer) particles to the light depolarization. Burton et al. (2015) recently presented triplewavelength polarization lidar observations in an aged and fresh dust layer performed with an airborne high-spectralresolution lidar (HSRL-2). The main goal of the paper is to present for the first time ground-based triple-wavelength polarization/Raman lidar observations (case studies) of the depolarization ratio of Saharan dust after long-range transport and to provide a high-quality statistical data set of dust 
depolarization ratios at 355,532 , and $1064 \mathrm{~nm}$. We conducted three campaigns on the Caribbean island of Barbados in the framework of SALTRACE. Two of them took place in the summer seasons of 2013 (SALTRACE-1) and 2014 (SALTRACE-3) to study Saharan dust layers advected from Africa towards North America. The third field campaign (SALTRACE-2) was performed in February-March 2014 to continue our research on mixed dust and smoke transport towards America during the winter half year (Ansmann et al., 2009; Baars et al., 2011; Tesche et al., 2011b; Rittmeister et al., 2017).

We begin our SALTRACE report with a short description of the SALTRACE experiment and instrumentation. The main part of Sect. 2 (and the Appendix) deals with the explanations of the triple-wavelength polarization lidar BERTHA. The results are presented in Sects. 3 and 4. In Sect. 3, three case studies are discussed. A statistical overview of the SALTRACE depolarization measurements is given in Sect 4 . The findings are compared with respective results from the foregoing SAMUM-1 and SAMUM-2 field campaigns and the Cloud-Aerosol Lidar with Orthogonal Polarization (CALIOP) satellite observations in the discussion Sect. 5. Concluding remarks are given in Sect. 6.

\section{SALTRACE campaigns and instrumentation}

\subsection{The SALTRACE project}

The SALTRACE field campaigns performed in the summer of 2013 and in the winter and summer of 2014 belong to the SAMUM-SALTRACE field campaign series. As shown and illustrated in Fig. 7 of Weinzierl et al. (2017), six comprehensive dust field campaigns have been conducted since 2006: SAMUM-1, SAMUM-2a and 2b, and SALTRACE-1, 2, and 3. The first SAMUM project, SAMUM-1 (Heintzenberg, 2009), took place in southern Morocco (May-June 2006) to investigate the role of freshly emitted dust in the climate system. SAMUM-2 (Cabo Verde; SAMUM-2a, JanuaryFebruary 2008; SAMUM-2b, May-June 2008; Ansmann et al., 2011) investigated the dust physicochemical, optical, and radiative properties of mixtures of biomass burning smoke and mineral dust (SAMUM-2a, winter transport regime) and of pure dust (SAMUM-2b, summer transport mode) after an atmospheric transport over 1000-3000 km (13 days after emission). During SALTRACE, we investigated the dust properties after atmospheric travel over 5-12 days and 5000-8000 km (Weinzierl et al., 2017).

As the logistically favorable field site for lidar observations, the Caribbean Institute for Meteorology and Hydrology was selected $\left(\mathrm{CIMH}, 13.1^{\circ} \mathrm{N}, 59.6^{\circ} \mathrm{W}, 110 \mathrm{~m}\right.$ above sea level, ma.s.1.), located in Husbands, in the northern part of the capital Bridgetown on the west coast of Barbados. The station is not influenced by any local (island) anthropogenic pollution because of the steady northeasterly airflow and the absence of strong pollution sources in the northern part of Barbados, upwind of the lidar station. In the summer months of June and July (SALTRACE-1 and 3), transported dust layers were observed. The SALTRACE lidar activities were complemented by shipborne observations along the main Saharan dust transport route over the tropical North Atlantic in April-May 2013 (Kanitz et al., 2014; Rittmeister et al., 2017; Ansmann et al., 2017); in situ observations of microphysical (size distribution, mass concentration, particle shape), chemical, and optical aerosol properties at Ragged Point $(20 \mathrm{~km}$ east of CIMH) at the east coast of Barbados (Kristensen et al., 2016; Wex et al., 2016); and airborne in situ aerosol observations and Doppler lidar measurements of aerosol layering and atmospheric wind fields (Chouza et al., 2015, 2016a, b; Weinzierl et al., 2017). The SALTRACE in situ observations include studies of the efficacy of aged desert dust to serve as cloud condensation nuclei (Kristensen et al., 2016; Wex et al., 2016; Weinzierl et al., 2017) as well as modeling studies of dust transport across the Atlantic (Chouza et al., 2016a; Ansmann et al., 2017) and the impact of the Caribbean island on the airflow and downward mixing of dust (Jähn et al., 2016; Chouza et al., 2016b).

\subsection{Meteorological conditions}

In Rittmeister et al. (2017), the dust transport from Africa towards the Caribbean is discussed. The main features of dust layering across the Atlantic described by the conceptual model (Karyampudi et al., 1999) are illuminated and compared with the shipborne SALTRACE lidar observations. According to the conceptual model (Karyampudi et al., 1999) hot, dry, dust-laden air masses emerge from the western coast of Africa as a series of large-scale pulses in the summer months. Associated with easterly wave activity, Saharan dust outbreaks occur as discrete episodic pulses, which generally last 3-5 days. These dust outbreaks are mostly confined to a well-mixed layer, the Saharan air layer (SAL), that often extends to $5-6 \mathrm{~km}$ in height over West Africa due to intense solar heating in summer months. The airborne dust is carried westward by the prevailing easterly flow in the latitude belt of $10-25^{\circ} \mathrm{N}$. As the dust plumes are advected further west in the predominantly easterly flow, the base of the SAL rises rapidly as it is undercut by the relatively clean northeasterly trade winds. The well-mixed SAL resides above the trade wind inversion layer which is on top of the marine aerosol layer (MAL). The dust transport takes usually 57 days across the Atlantic. The strong temperature inversion at the base of the SAL limits convective activity and consequently precludes the possibility of strong wet deposition, except during periods with deep convection and precipitation. 


\subsection{Triple-wavelength polarization lidar BERTHA}

We begin with a short historical overview of polarization lidar observations of tropospheric dust. The polarization lidar technique was applied to tropospheric aerosols for the first time in the early 1970s (McNeil and Carsweil, 1975). Systematic measurements of the depolarization ratio in desert dust layers started in the 1980s in eastern Asia (Kobayashi et al., 1985; Iwasaka et al., 1988) and demonstrated the importance of polarization lidar for dust monitoring. Consequently, the Asian Dust Lidar Network was established in the 1990s (Murayama et al., 2001; Shimizu et al., 2004). In Europe, systematic Saharan dust studies with polarization lidars began in the 1990s (Gobbi, 1998; Gobbi et al., 2000; di Sarra et al., 2001). Dust was investigated later on by means of polarization lidar in the framework of the European Aerosol Research Lidar Network (e.g., Ansmann et al., 2003). All of the ground-based observations, conducted before SALTRACE, were based on single-wavelength lidar observations, although several single-wavelength-lidar systems were combined during dedicated field campaigns such as SAMUM-1 and 2 (Freudenthaler et al., 2009; Groß et al., 2011b; Tesche et al., 2011a). In the majority of applications the laser wavelength was $532 \mathrm{~nm}$. Sugimoto and Lee (2006) presented the first ground-based dual-wavelength polarization lidar observations of dust performed at 532 and $1064 \mathrm{~nm}$. Airborne dual-wavelength polarization lidar observations (at 532 and $1064 \mathrm{~nm}$ ) were realized in Saharan dust aboard the Falcon of the Germany Aerospace Center during SAMUM-1 in 2006 (Freudenthaler et al., 2009). During SALTRACE, dual-wavelength polarization lidars were operated simultaneously at 355 and $532 \mathrm{~nm}$ (Kanitz et al., 2014; Groß et al., 2015; Rittmeister et al., 2017). And recently the first triple-wavelength polarization lidars were developed and performed dust observations at 355, 532, and $1064 \mathrm{~nm}$ aboard an aircraft (Burton et al., 2015) and on the ground (Haarig et al., 2016a).

The schematic structure of the lidar system BERTHA is shown in Fig. 1. Two Nd:YAG lasers transmit linearly polarized laser pulses at 355 and $1064 \mathrm{~nm}$ (first laser) and at $532 \mathrm{~nm}$ (second laser) with a repetition rate of $30 \mathrm{~Hz}$. Two linear polarizers are installed behind the laser and before the beam expander to further clean the polarization of the outgoing light. The pulse energies can be as high as $1000 \mathrm{~mJ}$ $(1064 \mathrm{~nm}), 800 \mathrm{~mJ}(532 \mathrm{~nm})$, and $120 \mathrm{~mJ}(355 \mathrm{~nm})$ in the ideal case of well-working optical elements in the transmission unit of the lidar. However, the pulse energies were only about $50 \%$ of these maximum values during the SALTRACE campaigns. Two lasers are used for two reasons: firstly to have a frequency-stabilized $532 \mathrm{~nm}$ laser for the implementation of the HSRL-channel and secondly to have a backup laser in the field campaign. The laser beams are aligned on an optical axis and directed through a beam expander. The beams are expanded tenfold and afterwards pointed into the atmosphere at an off-zenith angle of $5^{\circ}$. By using a tilt an- gle of $>3^{\circ}$, specular reflection by falling and horizontally aligned ice crystals no longer influences the measurements, as our experience shows.

A Cassegrain telescope with $53 \mathrm{~cm}$ diameter collects the backscattered light. The receiver field of view is $0.8 \mathrm{mrad}$.

The receiver unit was completely re-designed to measure the linear depolarization ratio at all three wavelengths. In addition, a high spectral resolution (HSR) channel was added (see Fig. 1). All detectors are photomultiplier tubes (PMTs) working in the photon counting mode (H10721P-110 from Hamamatsu). But for the $1064 \mathrm{~nm}$ channels the PMT R3236 from Hamamatsu is used at a temperature below $-30^{\circ} \mathrm{C}$ to reduce signal noise in the near infrared. The elastic backscatter signals (total signals) as well as the so-called crosspolarized signal components are detected at the three emitted wavelengths $(355,532,1064 \mathrm{~nm})$. Polarization filters, each adjusted orthogonal to the plane of linear polarization of the outgoing laser pulses, are placed in front of the detectors which enable the detection of the cross-polarized laser radiation at the three wavelengths. For these six elastic channels, interference filters with $1 \mathrm{~nm}$ FWHM (full width at half maximum) are placed in front of each PMT. The vibrationalrotational Raman signals at 387 and $607 \mathrm{~nm}$ (nitrogen) and $407 \mathrm{~nm}$ (water vapor, night time only) are detected as well. Interference filters with $3 \mathrm{~nm}$ FWHM are used at the Raman wavelengths. A double-grating monochromator enables the detection of pure rotational Raman signals from nitrogen and oxygen (J0, J6, and J12) from the $532 \mathrm{~nm}$ emission wavelength. Neutral density filters are placed in front of each detector to adjust the signal to the linear range of the detector to avoid dead time effects of the photomultipliers. Nevertheless the PMTs are tested in the lab to correct high counting rates for dead time effects if necessary (Engelmann et al., 2016).

The signals are detected with a range resolution of $7.5 \mathrm{~m}$ and a time resolution of 5 to $30 \mathrm{~s}$. A camera is used to visualize the overlap between the $532 \mathrm{~nm}$ laser beam and the receiver field of view (RFOV). The camera is permanently placed in the position of a receiving channel (see Engelmann et al., 2016). Complete overlap is reached at 800 $1000 \mathrm{~m}$ for the $532 \mathrm{~nm}$ related channels and approximately at $1500 \mathrm{~m}$ for the $355 \mathrm{~nm}$ related channels. The 355 and $532 \mathrm{~nm}$ backscatter coefficient is derived from the ratio of the elastic backscatter signal to the respective nitrogen Raman signal (387 or $607 \mathrm{~nm}$ ) and is therefore not much affected by the overlap profile. Even at $1064 \mathrm{~nm}$ we used the nitrogen Raman signal at $387 \mathrm{~nm}$ as the reference signal in the $1064 \mathrm{~nm}$ backscatter retrieval. Both signals are caused by backscattered laser-1 photons (see Fig. 1) so that almost the same overlap characteristics hold for both signals, and the overlap effects widely cancel out when forming the signal ratio. We used the sun photometer observations (Sect. 2.6) of the spectral slope of aerosol extinction for the correction of minor differential ( $387 \mathrm{~nm}$ vs. $1064 \mathrm{~nm}$ ) particle extinction effects in the backscatter retrieval. On clear (dustfree) days we checked the overlap function according to 


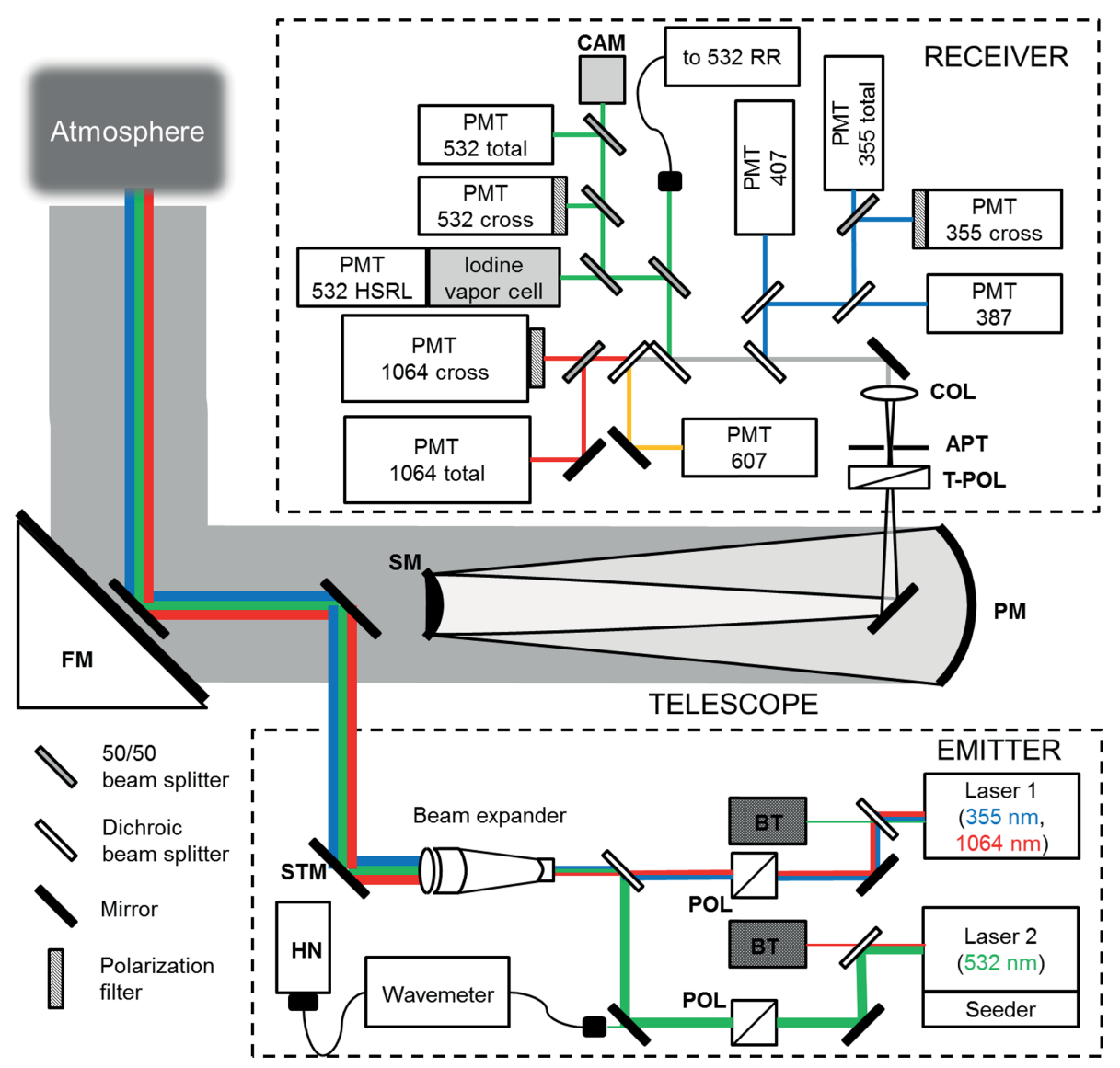

Figure 1. Sketch of BERTHA's emitter and receiver. All detection channels are photomultiplier tubes (PMTs, operated in the photon counting mode) and the numbers indicate the central wavelength of transmission in nanometers of the interference filter. Polarization filters are oriented perpendicular to the emitted state of polarization and are placed in front of the "cross" channels. The "total" channels measure the cross and the parallel part of the backscattered light. POL denotes polarizer to purify the laser polarization, BT denotes beam trap, HN denotes helium neon laser as reference for the wavemeter, STM denotes steering mirror with stepper motors to adjust the overlap, CAM denotes camera to visualize the overlap, FM denotes flat mirror (consisting of two mirrors, the small one for emitted pulses, the large one for backscattered light), PM stands for main or primary mirror and SM for counter or secondary mirror of the Cassegrain telescope, and TPOL means turnable polarization filter for $\Delta 90^{\circ}$ calibration, APT motorized aperture, and COL collimator. Finally RR denotes rotational Raman channel, and HSRL denotes the high-spectral-resolution lidar channel.

Wandinger and Ansmann (2002). Trustworthy results can be obtained at altitudes above about $400 \mathrm{~m}$ for the backscatter coefficient and above about $1000 \mathrm{~m}$ for the extinction coefficient, derived from the 387 and $607 \mathrm{~nm}$ nitrogen Raman signal profiles. To control the correct alignment, a telecover test (Freudenthaler, 2008) with eight segments (four inner and four outer) has been performed during SALTRACE-2 and in Leipzig in the autumn of 2014.

The focus of this article is on depolarization-ratio observations. In order to ensure a high quality of the data, the polarization sensitivity of the lidar system was characterized carefully. The polarization-sensitive transmission of the optical elements in the emitter and the receiver has been characterized. A detailed description of the polarization characterization can be found in Appendix A.
The basic lidar-derived quantity is the volume linear depolarization ratio defined as the ratio of cross- to co-polarized signal components (Gimmestad, 2008). The prefixes "co" and "cross" denote the planes of polarization (for which the receiver channels are sensitive) parallel and orthogonal to the plane of linear polarization of the transmitted laser pulses, respectively. In the case of BERTHA we measure the crosspolarized and total (cross + co-polarized) signal components and thus determine the co-polarized signal component from the cross-polarized and total signal components (more details are given in the Appendix).

The volume depolarization ratio at 355 and $532 \mathrm{~nm}$ is influenced by light depolarization by air molecules, aerosol, and cloud particles. To obtain the particle depolarization ratio a correction for molecular depolarization effects has to be applied (Biele et al., 2000). To account for molecular backscat- 
ter, extinction and depolarization contributions to the measured lidar signals we used the SALTRACE radiosonde observations at CIMH, which were performed twice a day (Sect. 2.7). The radiosonde height profiles of air temperature and pressure profiles permit the computation of the actual height profile of air molecule number concentration over Barbados.

The presence of cirrus is routinely used to check the consistence of the depolarization ratios at different wavelengths among each other. Because the size of the ice crystals is usually much larger than the laser wavelength, the measured optical properties are close together for the 355 to $1064 \mathrm{~nm}$ wavelength range. This can be used to evaluate the quality of the depolarization-ratio observations for each of the three wavelengths. Case study II in the next section will be an example for these routine checks.

An extended analysis of systematic uncertainties in the retrieved optical properties can be found in Freudenthaler et al. (2009), Freudenthaler (2016), Tesche et al. (2009, 2011a, b), and Bravo-Aranda et al. (2016). The error bars of the retrieval products given in the next sections show standard deviations considering the overall uncertainty.

\subsection{POLIS}

During the SALTRACE-1 campaign in the summer of 2013, the dual-wavelength polarization lidar POLIS (Portable Lidar System) of the Munich University (Groß et al., 2015) was operated at CIMH, about $50 \mathrm{~m}$ north of the BERTHA lidar. POLIS is a well-designed and characterized sixchannel polarization/Raman lidar and provides volume linear depolarization-ratio profiles at 355 and $532 \mathrm{~nm}$ with high accuracy (Freudenthaler et al., 2016; Bravo-Aranda et al., 2016). POLIS is used as the reference polarization lidar system in EARLINET calibration and quality-assurance activities. The deployment of both lidars at the same site was motivated by the fact that the 13-channel BERTHA lidar, which integrates the HSR lidar technique, Raman aerosol, water vapor, temperature profiling methods, and now in addition the multiwavelength depolarization-ratio profiling option in one system, is a complex lidar system with a large number of potential sources for uncertainties (see Appendix A). Therefore to avoid any risk and to guarantee a high-quality SALTRACE data set of multiwavelength depolarization-ratio profiles, we decided to run POLIS and BERTHA side by side during the entire SALTRACE-1 campaign at CIMH.

The full overlap of the laser beams of POLIS with the RFOV is at about 200 to $250 \mathrm{~m}$ above ground (Groß et al., 2016), so well within the marine boundary layer (MBL) and below the lofted Saharan air layer. The range resolution of the raw data is $3.75 \mathrm{~m}$, the temporal resolution $5-10 \mathrm{~s}$ depending on atmospheric conditions. The repetition rate of the frequency doubled and tripled Nd:YAG laser is $10 \mathrm{~Hz}$ with a pulse energy of $50 \mathrm{~mJ}$ at $355 \mathrm{~nm}$ and $27 \mathrm{~mJ}$ at $532 \mathrm{~nm}$ (see Table 1 for more details).
Table 1. Main system parameters of the BERTHA and POLIS lidar systems.

\begin{tabular}{lll}
\hline Property & BERTHA & POLIS \\
\hline Emitted wavelengths $(\mathrm{nm})$ & $355,532,1064$ & 355,532 \\
Pulse energy $(\mathrm{mJ})^{*}$ & $120+800+1000$ & $50+27$ \\
Repetition rate $(\mathrm{Hz})$ & 30 & 10 \\
Telescope & Cassegrain & Dall-Kirkham \\
Eff. telescope diameter (m) & 0.53 & 0.175 \\
Receiver field of view (mrad) & 0.8 & 2.5 \\
Detected wavelengths (nm) & & \\
- elastic (total) & $355,532,1064$ & \\
- co-polarized & & 355,532 \\
- cross-polarized & $355,532,1064$ & 355,532 \\
- inelastic (vib. Raman) & $387,407,607$ & 387,607 \\
- further & $532 \mathrm{HSRL}, 532 \mathrm{RR}$, & \\
Range resolution (m) & 7.5 & 3.75 \\
\hline
\end{tabular}

HSRL - high-spectral-resolution lidar; RR - rotational Raman.

* Internal attenuation are not taken into account for BERTHA, but for POLIS.

\subsection{CALIOP}

Spaceborne lidar observations of the $532 \mathrm{~nm}$ particle linear depolarization ratio are used for comparison with the $532 \mathrm{~nm}$ particle depolarization ratios from the ground-based lidar observations during SAMUM-1, SAMUM-2, and SALTRACE. We analyzed all CALIOP observations (CALIPSO, 2016) for well-defined areas over Morocco $\left(26-31^{\circ} \mathrm{N}, 3-8^{\circ} \mathrm{W}\right)$, in the Cabo Verde region $\left(13-18^{\circ} \mathrm{N}, 21-26^{\circ} \mathrm{W}\right)$, and around Barbados $\left(10-15^{\circ} \mathrm{N}, 55-60^{\circ} \mathrm{W}\right)$, performed in June 2013 (1113 overpasses), July 2013 (15-17 overpasses), June 2014 (13-16 overpasses), and July 2014 (11-14 overpasses). We checked all day and night overpasses (scenes) for the presence of dust and averaged all dusty signal profiles within the defined areas. In order to retrieve the dust depolarizationratio profiles for each overpass, only the observations characterized as dust from the CALIPSO subtype algorithm (Omar et al., 2009) are used. In these profiles, the particle linear depolarization ratio is recalculated from L2 perpendicular and total backscatter profiles, to improve the accuracy compared to the original CALIPSO L2-Version 3 product, which has a known error (Tesche et al., 2013; Amiridis et al., 2013). Furthermore, several quality control procedures and filtering criteria are applied in the data set as described in Marinou et al. (2017).

In the next step, we selected those height ranges (below $6 \mathrm{~km}$ height) of the monthly mean profiles in which the depolarization ratios were almost height-independent and computed the column-averaged $532 \mathrm{~nm}$ particle depolarization ratio for these specific height ranges. These column values are used for comparison in Sects. 4 and 5. The selected height ranges with almost height-independent depolarization ratios extended from $800-1000$ to $3700-5600 \mathrm{~m}$ a.s.l. (Morocco), from 1500-2300 to 4800-5400 m a.s.l. (Cabo Verde), and from 2500 to $3200-4200 \mathrm{~m}$ a.s.l. (Barbados). At lower heights, contamination with aerosol pollution and/or marine 
particles caused a significantly lower depolarization ratio. Therefore these lower heights were not considered in the dust-related depolarization data analysis.

\subsection{AERONET photometers}

Three sun photometers were run during the SALTRACE campaign at CIMH lidar station in 2013. Besides two CIMEL sun-sky photometers of AERONET (Aerosol Robotic Network; Holben et al., 1998) from TROPOS and the University of Valladolid (see Barbados_SALTRACE, AERONET, 2016), an automatic sun-sky radiometer of the Meteorological Institute of the University of Munich measured the spectral aerosol optical thickness (AOT) and sky radiances (Toledano et al., 2009, 2011). The photometers covered a wavelength range from 340 to $1640 \mathrm{~nm}$. The TROPOS photometer was operated from June 2013 to July 2014 (with an interruption from October 2013 to February 2014 caused by a damage of the sun photometer). Another photometer of AERONET is installed at Ragged Point (east coast of Barbados) in the vicinity of the Barbados Cloud Observatory (Stevens et al., 2016). The Ragged Point photometer has performed measurements since 2007.

\subsection{Radiosonde profiling}

As during the SAMUM-1 and 2 campaigns, we regularly performed radiosonde observations. The Vaisala RS92 radiosondes measuring height profiles of temperature, air pressure, relative humidity, wind speed, and direction up to heights above $20 \mathrm{~km}$ were launched around local noon (15:00-16:00 UTC, 11:00-12:00 local time, LT) and after sunset (23:00-24:00 UTC, 19:00-20:00 LT). In total 133 radiosonde ascends were conducted at CIMH, 56, 35, and 42 during the SALTRACE-1, 2, and 3 campaigns, respectively.

\section{SALTRACE case studies}

Three case studies are presented to discuss the quality and accuracy of the spectrally resolved depolarization-ratio observations with BERTHA. The first case study from summer 2013 offers the opportunity of direct comparisons with the Munich lidar system POLIS, measured at the same field site in the framework of the SALTRACE-1 campaign (Groß et al., 2015). In summer 2014 only the lidar system BERTHA measured the transported Saharan dust. Two cases are shown: the first with a cirrus cloud, where the depolarization ratio is known, and the second, where the same dust reached the North American continent 1 week later and was measured by the HSRL-2 (Burton et al., 2015).

\subsection{Case study I: Comparison of POLIS and BERTHA observations (11 July 2013)}

A strong and long-lasting dust outbreak occurred from 9 to 13 July 2013. Figure 2 shows the BERTHA observations of the lofted SAL in the evening of 10 July 2013 (19:1520:45 LT). The African air mass crossed Barbados with 15$20 \mathrm{~m} \mathrm{~s}^{-1}$ wind speed from east to west according to the radiosonde profiles (Fig. 2a). The relative humidity ranged from 30 to $50 \%$ in the dust layer between 1.75 and $4.6 \mathrm{~km}$ height (Fig. 2c). The moist marine aerosol layer (MAL), indicated by high relative humidity around $80-90 \%$, reached to $1.75 \mathrm{~km}$ height on this evening. The MBL is the convective part of the MAL and is often topped with trade wind cumuli. The MAL extends up to the base of the SAL, which coincides with the trade wind inversion zone. Downward mixing of dusty air into the upper part of the marine aerosol layer is visible in Fig. 2d (green colors between 0.5 and $1.5 \mathrm{~km}$ a.s.l.). This layer is also called the intermediate layer (Jung et al., 2013), due to its location between the convective boundary layer and the SAL. The heterogeneous structures in the $532 \mathrm{~nm}$ volume depolarization height-time display in Fig. $2 \mathrm{~d}$ below $1.5 \mathrm{~km}$ height are caused by island effects. Differences in orography and heat release over land and ocean surfaces disturb the air mass flow in the lowest part of the atmosphere (Jähn et al., 2016). Such vertical mixing features were not observed during the SALTRACE shipborne lidar observations over the open Atlantic in May 2013 (Kanitz et al., 2013; Rittmeister et al., 2017). The backward trajectories in Fig. 3 at $3000 \mathrm{~m}$ height indicate dust uptake over desert areas of northwestern Africa so that contamination with anthropogenic pollution was probably low. The dusty air masses traveled 5-7 days across the Atlantic to Barbados.

Figure 4 presents the particle optical properties obtained with the conventional Raman lidar technique (Ansmann et al., 1992). Typical features of Saharan dust were observed (Mattis et al., 2002; Papayannis et al., 2005; Tesche et al., 2011a; Preißler et al., 2011; Veselovskii et al., 2016; Hofer et al., 2017). The backscatter and extinction coefficients at 355 and $532 \mathrm{~nm}$ are similar and the dust $1064 \mathrm{~nm}$ backscatter coefficient is significantly lower than the respective $532 \mathrm{~nm}$ backscatter coefficient in the SAL. The observed Saharan dust lidar ratios accumulate in the 50-60 sr range at 355 and $532 \mathrm{~nm}$. Below $1.75 \mathrm{~km}$ height a mixture of marine particles and dust particles prevailed so that the lidar ratio decreased. For pure marine conditions, the lidar ratio would be close to 15-25 sr (Flamant et al., 1998; Groß et al., 2011b; Burton et al., 2012; Dawson et al., 2015; Rittmeister et al., 2017; Haarig et al., 2017). The SAL AOT was about 0.3 at 355 and $532 \mathrm{~nm}$ on this day. Figure 5 shows the particle linear depolarization-ratio profiles obtained with POLIS and BERTHA on 11 July 2013, 00:00-00:45 UTC. The POLIS backscatter coefficients in Fig. 5a are computed by applying the Klett method with a dust lidar ratio of $55 \mathrm{sr}$ within the SAL and 30-40 sr below the SAL (Groß et al., 2015). 


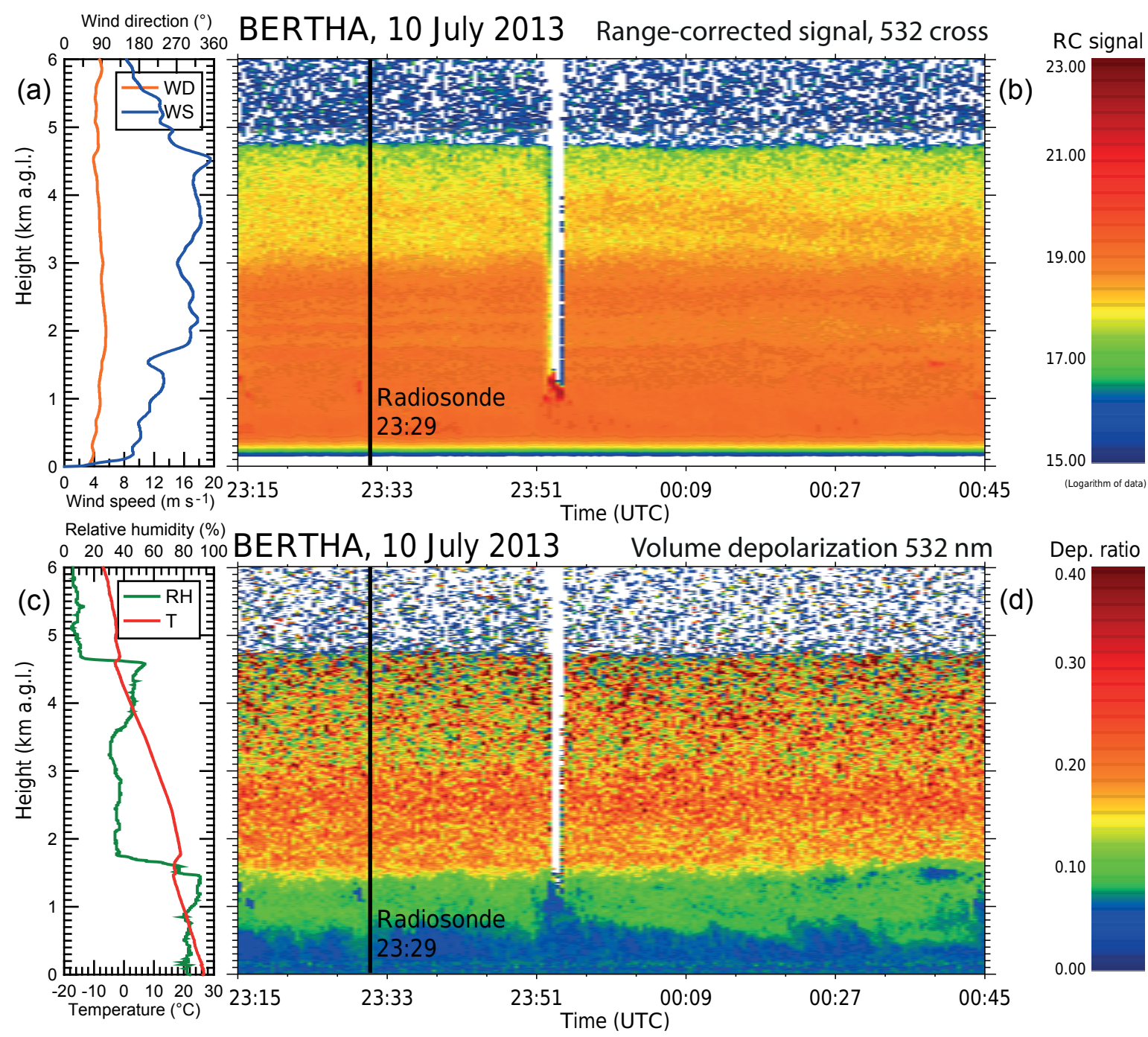

Figure 2. Saharan air layer (from 1.5 to $4.7 \mathrm{~km}$ height above ground level) above the marine boundary layer. Panel (b) shows the rangecorrected cross-polarized $532 \mathrm{~nm}$ backscatter signal with temporal and vertical resolutions of $30 \mathrm{~s}$ and $7.5 \mathrm{~m}$, respectively. Panel (d) shows the $532 \mathrm{~nm}$ volume linear depolarization ratio. The lidar observation was performed on 10 July 2013, 19:15-20:45 LT. A radiosonde was launched at 19:29 LT (indicated by black vertical lines). The radiosonde profiles of wind speed (WS) and wind direction (WD) are shown in panel (a), the profiles of relative humidity $(\mathrm{RH})$ and temperature $(T)$ in panel (c).

The Raman lidar method is used in the computation of the backscatter profiles from the BERTHA observations.

As can be seen, very good agreement is obtained regarding the volume linear depolarization ratio at 355 and $532 \mathrm{~nm}$ (Fig. 5b). In the computation of the particle depolarization ratio, the particle backscatter coefficients are required and cause further uncertainty. This impact is most sensitive at $355 \mathrm{~nm}$. The apparent noise in the $355 \mathrm{~nm}$ particle depolarization-ratio profiles is caused by the backscatter coefficients used. At 355 and $532 \mathrm{~nm}$ the SAL mean particle depolarization ratio can be compared between BERTHA ( 0.25 and 0.28 at 355 and $532 \mathrm{~nm}$, respectively) and POLIS (0.26 and 0.27). Both systems agree very well. Only BERTHA measured at $1064 \mathrm{~nm}$, and derived a SAL mean particle de- polarization ratio of 0.22 . Below the SAL, all particle depolarization ratios decrease. The down-mixed dust prevents a decrease towards pure marine values of $0.02-0.03$ (Groß et al., 2011b).

In Fig. 5c, profiles of the ratio of particle depolarization ratios $(355 \mathrm{~nm}$ over $532 \mathrm{~nm}$ in blue, $1064 \mathrm{~nm}$ over $532 \mathrm{~nm}$ in red) are shown. The mean values are $0.81(1064 / 532 \mathrm{~nm})$ and $0.88(355 / 532 \mathrm{~nm})$. The observed height independence of the particle depolarization ratios at all three wavelengths and of the less noisy ratio of the 1064-to-532 nm depolarization ratios implies vertically homogeneous dust size-shape characteristics. An impact of gravitational settling leading to a decrease of coarse-mode dust concentration in the SAL top region after 5-10 days of travel, which would show up in a 


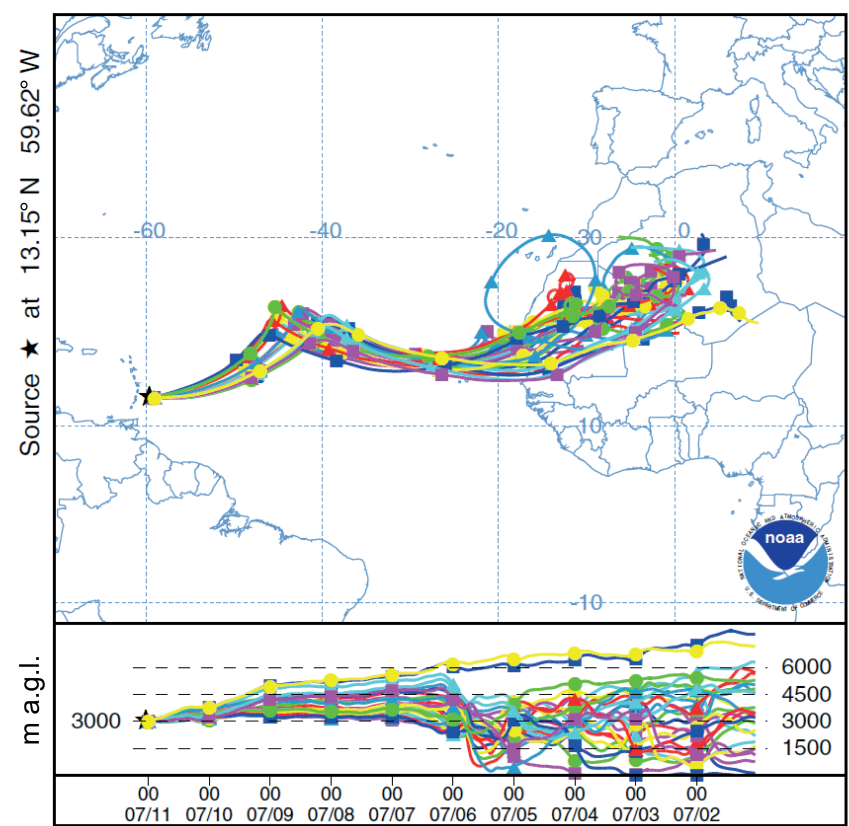

Figure 3. Ensemble of 10-day backward trajectories (Stein et al., 2015; HYSPLIT, 2016) for 11 July 2013, 01:00 UTC, arriving at 3000 m over Barbados.

significant change in the spectral slope of the depolarization ratio (especially at $1064 \mathrm{~nm}$ ), is not visible. This corroborates the hypothesis proposed by Gasteiger et al. (2017) that heating of the dust particles and turbulent mixing of the SAL air masses during daytime hours may widely reduce coarsemode dust removal by gravitational settling of particles.

\subsection{Case study II: Measurements of the dust layer and a cirrus (20 June 2014)}

During SALTRACE-3 in 2014, POLIS was not available. Cirrus depolarization measurements were used to check the quality of triple-wavelength depolarization observations over time. Ice crystals are very large compared to the laser wavelengths so that the spectral dependence of backscattering, extinction, and depolarization properties is rather weak.

Figure 6 presents a cirrus measurement performed on 20 21 June 2014. The cirrus layer between 12 and $14 \mathrm{~km}$ height was optically thin with an AOT of 0.1. The wavelengthindependent backscatter coefficients of up to $3.5 \mathrm{Mm}^{-1} \mathrm{sr}^{-1}$ at cirrus center indicate peak particle extinction values of $100-120 \mathrm{Mm}^{-1}$. The extinction values are obtained by applying a multiple-scattering-corrected cirrus lidar ratio of 30-35 sr to the cirrus backscatter coefficients (Haarig et al., 2016b). The extinction measured with the Raman channels would need a too-large smoothing length in the thin cirrus.

As shown in Fig. 6b, depolarization ratios within the cirrus (above $12.2 \mathrm{~km}$ height) for 532 and $1064 \mathrm{~nm}$ are almost equal up to cloud top. The $1064 \mathrm{~nm}$ particle linear depolarization ratio is close to 0.5 and height-independent from 12.2
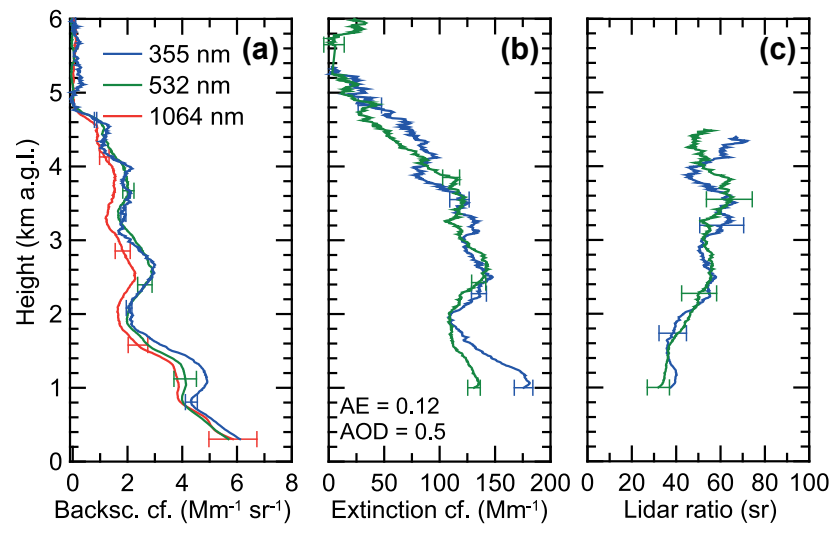

Figure 4. 45 min mean profiles of (a) the particle backscatter coefficient at three wavelengths, (b) extinction coefficient at two wavelengths, and (c) extinction-to-backscatter ratio (lidar ratio) at two wavelengths, measured with BERTHA on 11 July 2013, 00:0000:45 UTC. Error bars indicate the retrieval uncertainty (1 standard deviation). The vertical signal smoothing window length is $200 \mathrm{~m}$ (backscatter coefficient) and $1000 \mathrm{~m}$ (extinction coefficient, lidar ratio). The column values of the Angström exponent (AE $440-870 \mathrm{~nm}$ ) and the aerosol optical depth (AOD) from the closest AERONET observation are indicated.

to $13.3 \mathrm{~km}$ height. The noisy $355 \mathrm{~nm}$ particle depolarization ratio is less trustworthy, but close to the 532 and $1064 \mathrm{~nm}$ depolarization ratios at least in the cirrus backscatter center from 12.4 to $12.8 \mathrm{~km}$ height. This consistent cirrus measurement of wavelength-independent cirrus backscatter and depolarization corroborate that BERTHA was performing well and that our dust observations below $5 \mathrm{~km}$ height are trustworthy.

Figure 7 shows the aerosol layers in the lower troposphere on this cirrus day. A $3 \mathrm{~km}$ thick SAL was present above the marine aerosol layer. Relative humidities of $40-50 \%$ in the SAL were comparably high and suggest some mixing with moist marine air.

The HYSPLIT backward trajectories in Fig. 8 corroborate this hypothesis. A total of 4 days before arriving at Barbados, the air masses at $2.5 \mathrm{~km}$ height had the chance of vertical mixing with marine particles or African pollution. Only the uppermost dust layer (3-4 km height over Barbados, trajectories not shown) seems to contain pure dust. The air masses arriving at $3.5 \mathrm{~km}$ height were above $6 \mathrm{~km}$ over desert areas in western Africa.

Figure 9 presents the particle optical properties derived from the BERTHA observations. A steady and almost monotonic decrease of the backscatter coefficients with height was found. The extinction coefficients at 355 and $532 \mathrm{~nm}$ are again very close and the SAL AOT was about 0.25 . The lidar ratios range from 40 to $50 \mathrm{sr}$ in the layer from 1 to $3 \mathrm{~km}$ height, which probably contained some marine and anthropogenic haze particles, and were higher with values of 50$60 \mathrm{sr}$ in the uppermost pure dust layer (3-4 km height). 


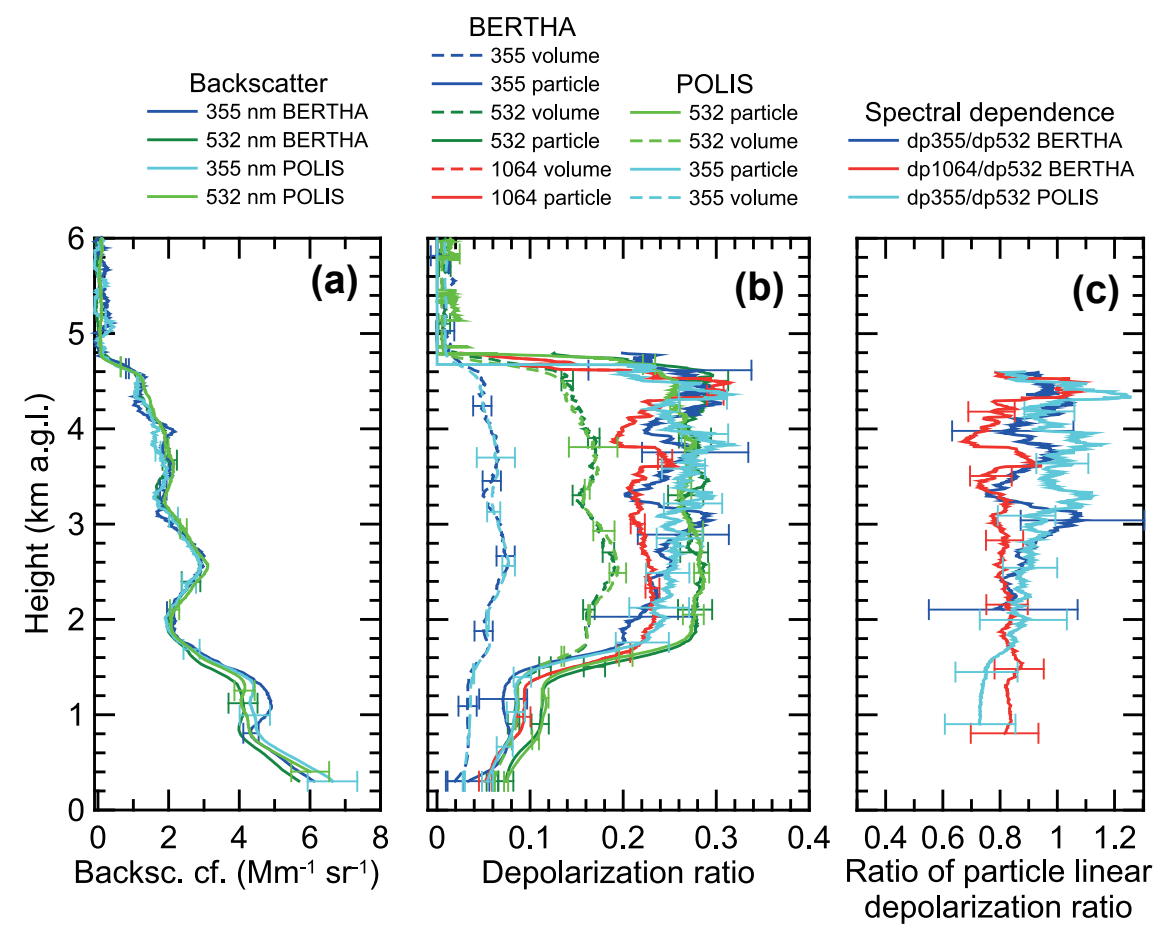

Figure 5. Comparison of POLIS and BERTHA depolarization-ratio observations. Shown are 45 min mean profiles of (a) the particle backscatter coefficient at 355 (POLIS light blue, BERTHA dark blue) and $532 \mathrm{~nm}$ wavelength (POLIS light green, BERTHA dark green); (b) the volume (dashed curves) and particle linear depolarization ratio (solid lines) at $355 \mathrm{~nm}$ (POLIS light blue, BERTHA dark blue), $532 \mathrm{~nm}$ (POLIS light green, BERTHA dark green), and $1064 \mathrm{~nm}$ (BERTHA, red line, equal volume and particle depolarization-ratio profiles); and (c) the ratio of the 355 to $532 \mathrm{~nm}$ particle depolarization ratio (POLIS light blue, BERTHA dark blue) and 1064 to $532 \mathrm{~nm}$ particle depolarization ratio (BERTHA, red). POLIS and BERTHA observations were taken simultaneously on 11 July 2013, 00:00-00:45 UTC. Error bars indicate the retrieval uncertainty ( 1 standard deviation). The vertical signal smoothing window length is $200 \mathrm{~m}$ (BERTHA, POLIS).
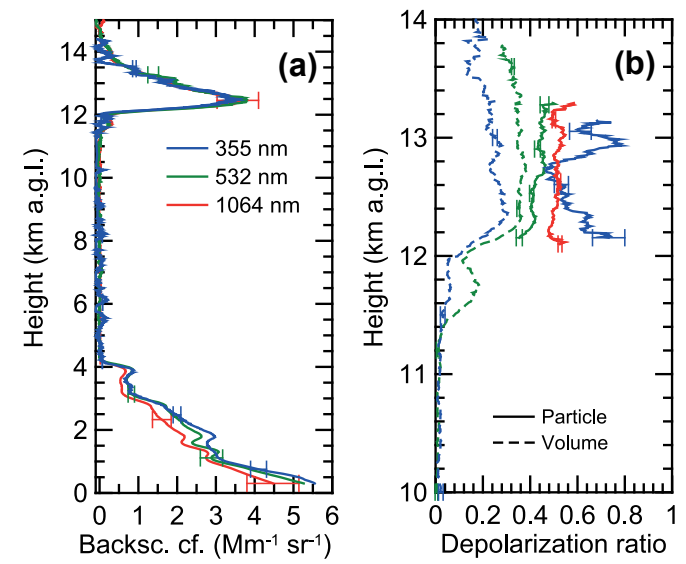

Figure 6. (a) Aerosol layers below $4 \mathrm{~km}$ height and cirrus layer from 12 to $14 \mathrm{~km}$ height in terms of particle backscatter coefficient at three wavelengths observed with BERTHA on 20-21 June 2014, 23:10-02:10 UTC (signal averaging period), and (b) cirrus ice crystal depolarization ratio (solid lines, volume depolarization ratio as dashed lines) at three wavelengths. At $1064 \mathrm{~nm}$ the volume depolarization ratio is equal to the particle depolarization ratio. The vertical signal smoothing length is $200 \mathrm{~m}$. Error bars show the relative uncertainty in the retrievals (1 standard deviation).
The height profiles of the 532 and $1064 \mathrm{~nm}$ particle depolarization ratio show slightly different profile shapes (Fig. 9c). The $1064 \mathrm{~nm}$ depolarization ratio decreases slightly with height whereas the $532 \mathrm{~nm}$ increases with height. Since the $1064 \mathrm{~nm}$ depolarization ratio is very sensitive to coarsemode particles, the decrease of the $1064 \mathrm{~nm}$ depolarization ratio (and of the ratio of 1064-to-532 nm depolarization ratios, Fig. 9d) may be related to a decreasing coarse-mode mean radius of the particles with height. The $532 \mathrm{~nm}$ depolarization ratio seems to be relatively insensitive against small changes in the coarse-mode size distribution (Mamouri and Ansmann, 2017). The $532 \mathrm{~nm}$ depolarization ratio for coarse mode particles is always in the range of 0.35-0.4. The slightly lower $532 \mathrm{~nm}$ depolarization values around $2 \mathrm{~km}$ height may again indicate a different history of the dust transport. The more fine-mode sensitive depolarization ratios (355 and $532 \mathrm{~nm}$ ) and the respective ratio of $355-$ to- $532 \mathrm{~nm}$ depolarization ratios show an almost height-invariant behavior when ignoring the noise in the $355 \mathrm{~nm}$ depolarization-ratio profile (Fig. 9d). 

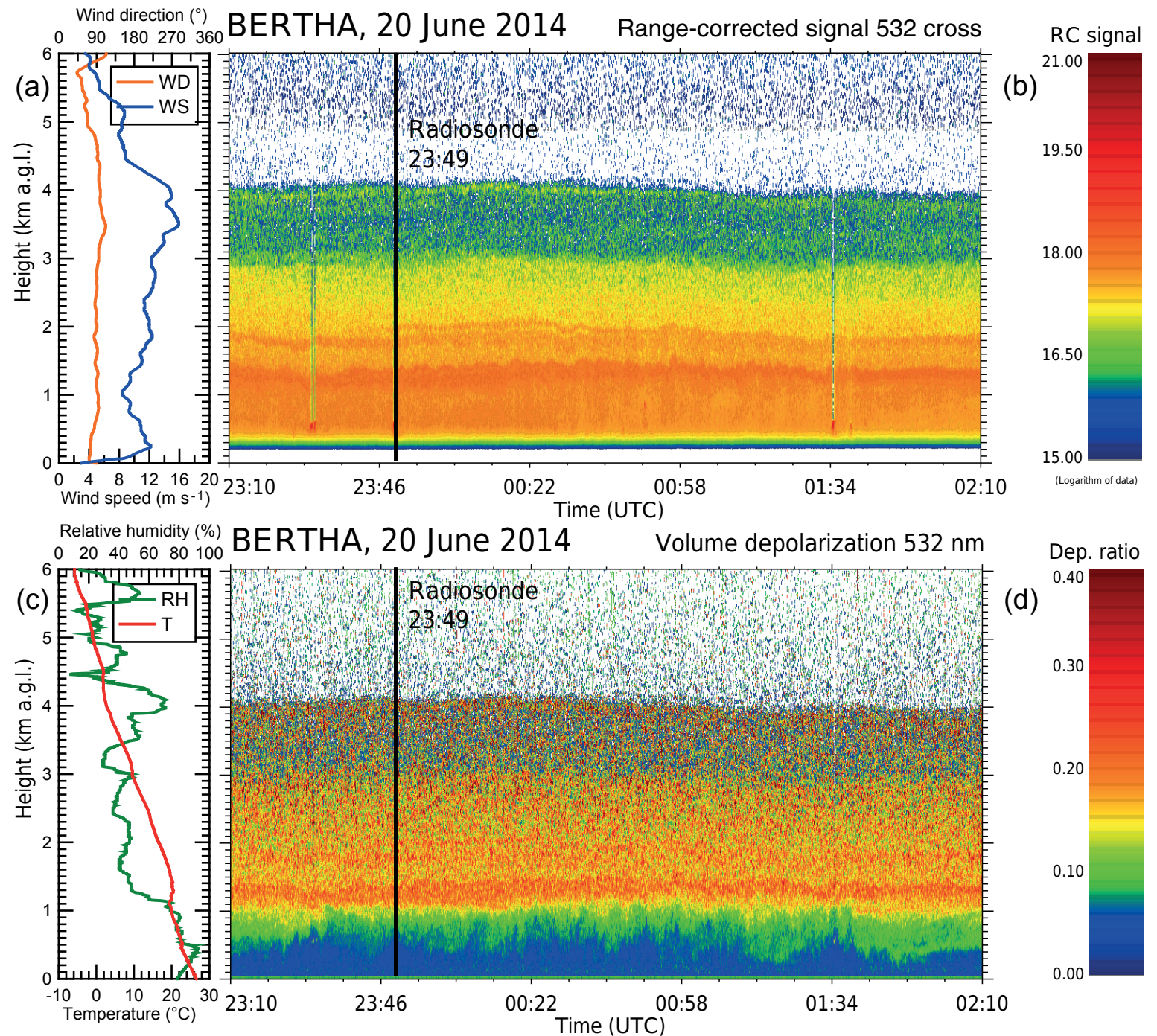

Figure 7. Saharan air layer (from 1 to $4 \mathrm{~km}$ height) above the marine boundary layer. The same parameters as in Fig. 2 are shown. The lidar observation was performed on 20 June 2014, 19:10-22:10 LT. The radiosonde was launched at 19:49 LT (indicated by black vertical lines).

\subsection{Case study III: Dust transport from Africa to Missouri over 12000 km (6 July 2014)}

A unique case was observed during SALTRACE-3 on 6 July 2014. A $3 \mathrm{~km}$ deep dust layer crossed Barbados and traveled westward towards the United States (see backward trajectories in Fig. 10 and time-height display of the BERTHA observations in Fig. 11). Coincidentally, this aged dust layer was observed with an airborne triple-wavelength polarization lidar (high-spectral-resolution lidar HSRL-2) 1 week later (Burton et al., 2015). We use this unexpected opportunity to compare the triple-wavelength depolarization observations of aged dust after long-range transport over $6000 \mathrm{~km}$ (Barbados) and $12000 \mathrm{~km}$ (Missouri, midwestern USA). Rather low relative humidities around $20 \%$ were measured with radiosonde in the lofted SAL (see Fig. 11c), suggesting almost no interference with cloud formation and associated upward mixing of marine air into the lower part of the SAL. High wind speeds around $18 \mathrm{~m} \mathrm{~s}^{-1}$ prevailed above $2.5 \mathrm{~km}$ height over Barbados. The 12.5-day backward trajectories indicate that the dust observed over Barbados at 2.5 and $3.5 \mathrm{~km}$ height descended towards 1.6 and $2.4 \mathrm{~km}$ height over Missouri, after crossing Yucatán (Mexico), Texas, and Oklahoma. After leaving the African continent, the dust layers arrived after 5 and 12 days over Barbados and Missouri, respectively.

Figure 12 shows the aerosol optical properties derived from the BERTHA measurements. The triple-wavelength particle linear depolarization observations performed over Missouri are added. The backscatter, extinction, and lidar ratio profiles again show typical dust optical properties. The SAL AOT was about 0.3 over Barbados on this day. The backscatter and extinction coefficients were roughly 25 


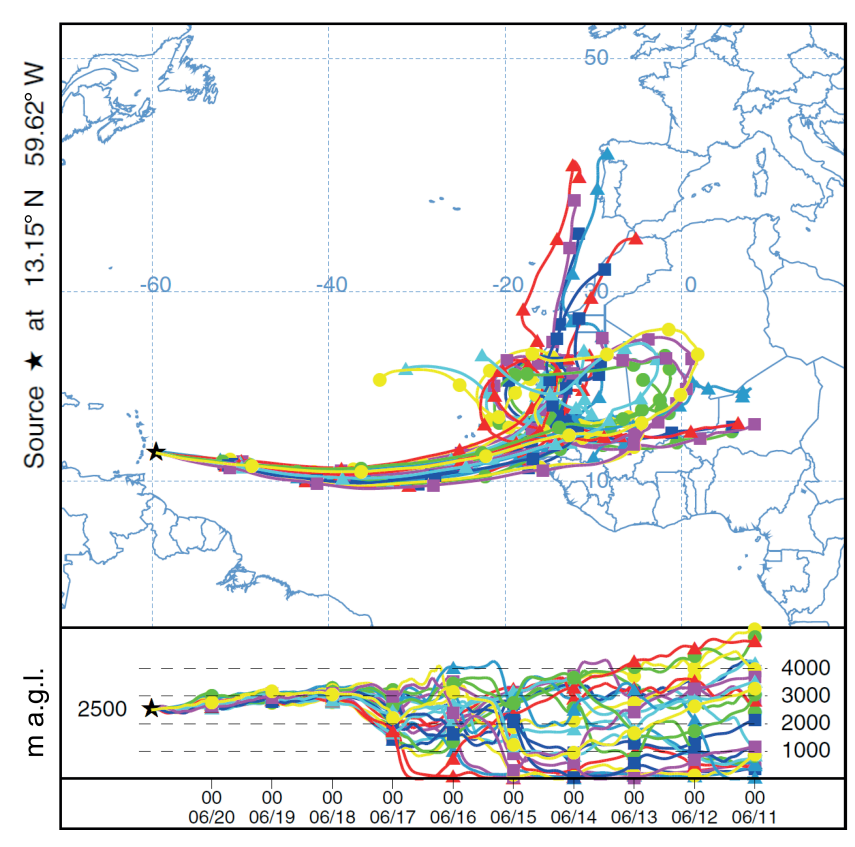

Figure 8. Ensemble of 10-day HYSPLIT backward trajectories for 21 June 2014, 00:00 UTC, arriving at $2500 \mathrm{~m}$ over Barbados.

$30 \%$ lower in the lofted dust layer over Missouri compared to the values measured over Barbados 1 week before.

An excellent agreement between the two lidar data sets of depolarization-ratio profiles was found (Fig. 12c). When comparing the values in the layers from 2.5 to $4.0 \mathrm{~km}$ height over Barbados with the values in the layer from 1.5 to $2.0 \mathrm{~km}$ height over Missouri, both lidars found similar depolarization ratios. At $532 \mathrm{~nm}(0.28$, BERTHA; 0.30, HSRL-2) and $1064 \mathrm{~nm}$ (0.26, BERTHA; 0.27-0.28, HSRL-2), the depolarization ratio over Barbados is slightly lower. The $355 \mathrm{~nm}$ depolarization ratio measured with BERTHA with a larger systematic uncertainty is around 0.24 . It is higher than over Missouri (0.21, HSRL-2). But the spectral behavior (Fig. 12d) of the $1064 \mathrm{~nm}$ to the $532 \mathrm{~nm}$ depolarization ratio was the same over Barbados and Missouri (0.91). The 355 / 532 ratio of depolarization ratios decreased between Barbados and the US.

Note also the higher depolarization ratios in the planetary boundary layer over Missouri (Fig. 12c). Probably, new soil dust particles were injected into the continental planetary boundary layer and then mixed upward into the lofted aged SAL over the United States. This entrainment of fresh coarse dust especially influences the $1064 \mathrm{~nm}$ depolarization ratio. Fine-mode pollution is released as well over the United States, and upward mixing and entrainment of pollution aerosol into the SAL affects the $355 \mathrm{~nm}$ depolarization ratio most sensitively. Nevertheless, the agreement is surprisingly good. Even after 7 days of travel from Barbados to the midwestern United States, the Saharan aerosol widely preserved its dust characteristics. No significant height depen- dence of the optical properties (lidar ratio, depolarization ratio, ratio of depolarization ratios) is visible in the main parts of the layer over both sites.

\section{SALTRACE statistical overview}

Figure 13 provides an overview of all triple-wavelength depolarization-ratio observations with BERTHA during the summer SALTRACE campaigns. SAL mean values of 8 evening sessions (SALTRACE-1, summer 2013) and 13 evening sessions (SALTRACE-3, summer 2014) are shown. The respective mean values derived from the BERTHA observations in June 2013 and 2014 and July 2013 and 2014 are shown as horizontal lines. In addition, monthly means of the SAL column dust depolarization ratio obtained from spaceborne lidar CALIOP observations at $532 \mathrm{~nm}$ in the Barbados region $\left(10-15^{\circ} \mathrm{N}, 55-60^{\circ} \mathrm{W}\right)$ are presented.

The number of evening observations with a complete set of depolarization ratios at all three wavelengths is comparably low for SALTRACE-1 (2013) because of many days with rainy and cloudy weather, days without dust, and also due to problems with one of the lasers. In 2014, 13 evening data sets of triple-wavelength depolarization-ratio profiles out of a total of 21 possible evening lidar sessions could be used for the statistics in Fig. 13. Fewer days with closed cloud decks and rain periods hampered observations in 2014. The 5-week SALTRACE-1 field phase was embedded in a typical tropical wet season. Short-term dust episodes were frequently interrupted by rainy weather. Radiosonde profiles often showed different wind directions from south to northeast within the $3-5 \mathrm{~km}$ thick Saharan dust layers until 9-10 July 2013. Cloud formation and activation of dust particles to serve as cloud condensation nuclei, as well as rain and corresponding washout, probably significantly influenced the dust characteristics during the long-range transport across the Atlantic. A pronounced, well-defined dust outbreak lasting several days was observed only from 9 to 13 July during the SALTRACE-1 campaign in 2013. Most of the July 2013 observations in Fig. 13 were taken during this final SALTRACE-1 dust outbreak. In contrast, more homogeneous and vertically well-structured dust outbreaks were observed in June and July 2014. The summer of 2014 was an extraordinary dry season in the Barbados area and over the tropical Atlantic. Cloud processing and washout by rain was strongly suppressed in the summer of 2014. Continuous and almost undisturbed dust transport from Africa towards the Caribbean occurred.

The fluctuations in the individual depolarization-ratio values in Fig. 13 partly reflect the impact of cloudy and rainy weather. The mean values (horizontal lines) for July 2013 (with the well-defined dust outbreak) and June and July 2014 differ significantly from the ones for June 2013 for the wavelengths of 532 and $1064 \mathrm{~nm}$. On average, the 532 and $1064 \mathrm{~nm}$ particle depolarization ratios accumulated in 


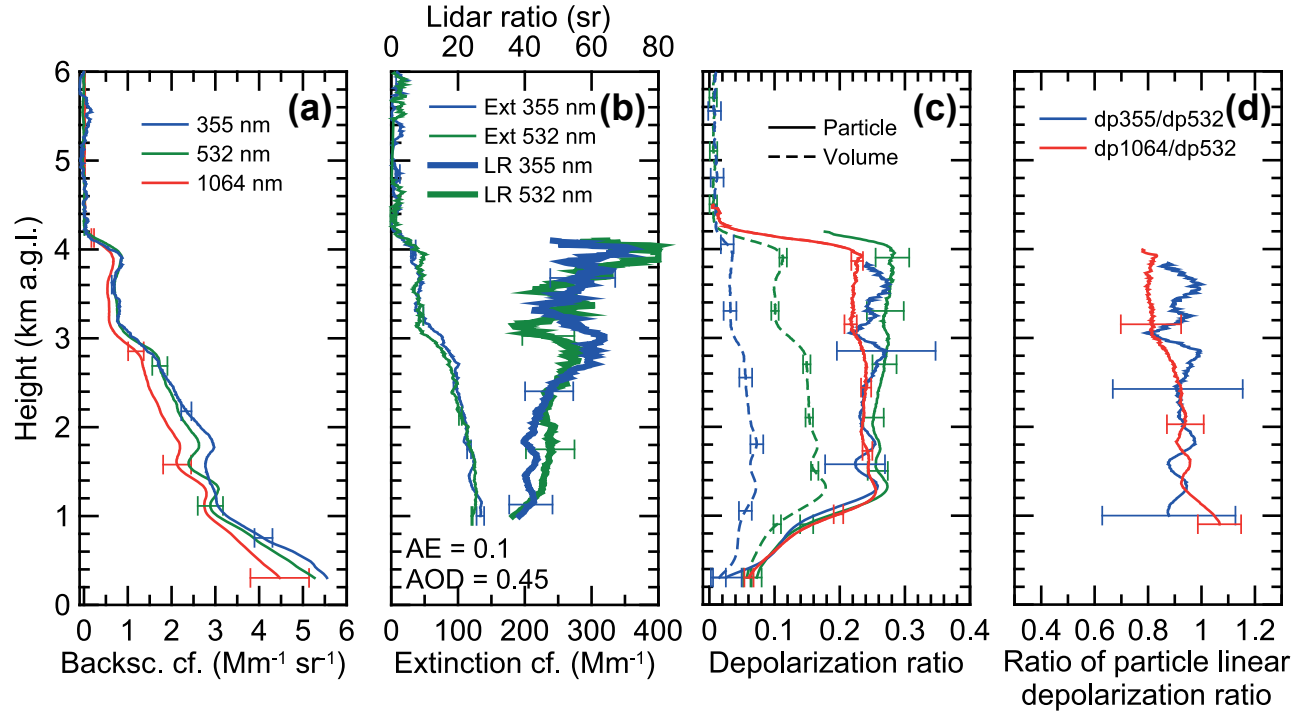

Figure 9. $3 \mathrm{~h}$ mean profiles of (a) the particle backscatter coefficient at three wavelengths, (b) the extinction coefficient and lidar ratio at two wavelengths, (c) the volume and particle linear depolarization ratio at three wavelengths, and (d) the ratio of the 355 to $532 \mathrm{~nm}$ and 1064 to $532 \mathrm{~nm}$ particle depolarization ratio. The lidar observation was performed on 20-21 June 2014, 23:10-02:10 UTC. The vertical signal smoothing window length is $200 \mathrm{~m}$ (backscatter coefficient, depolarization ratio) and $750 \mathrm{~m}$ (extinction coefficient, lidar ratio). Error bars indicate the retrieval uncertainty.

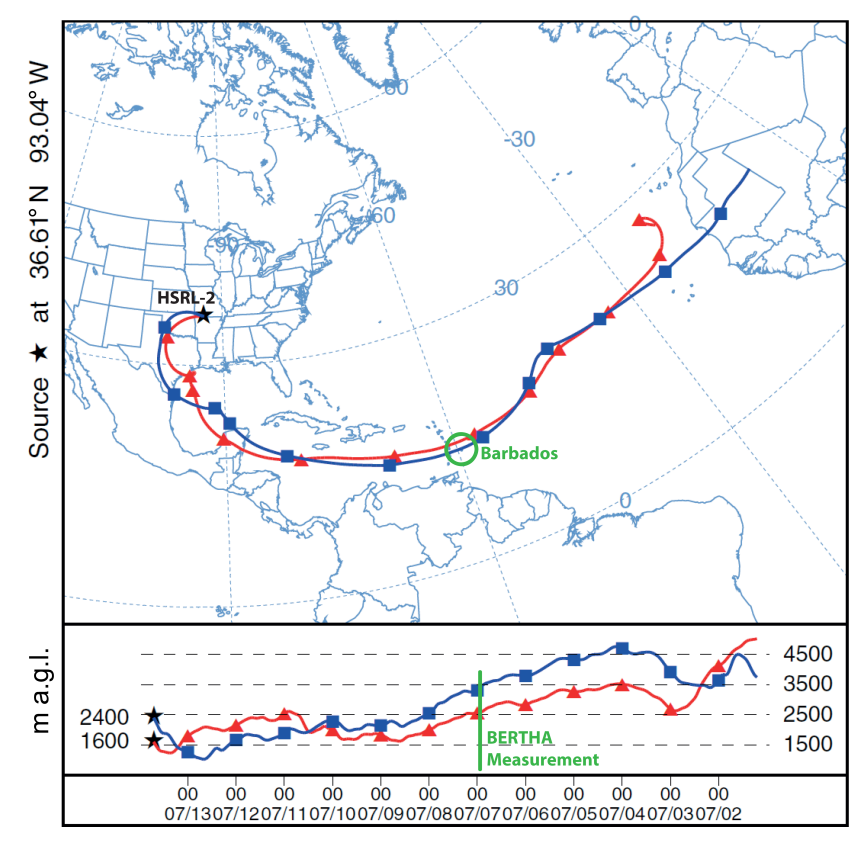

Figure 10. 12.5-day HYSPLIT backward trajectories for 13 July 2014, 17:00 UTC, arriving at $1600 \mathrm{~m}$ (red) and $2400 \mathrm{~m}$ (blue) over southern Missouri (midwestern United States). The location (Barbados) and time of the corresponding BERTHA lidar measurement is indicated by a green vertical line.

the $0.28-0.30$ and $0.22-0.26$ ranges, respectively, during the more dry and less cloud- and rain-affected periods. A similar contrast (wet 2013 vs. dry 2014 months) is observed with CALIOP. The CALIOP monthly means include SAL column values around Barbados $\left(10-15^{\circ} \mathrm{N}, 55-60^{\circ} \mathrm{W}\right)$. The large standard deviation bars of the CALIOP monthly means in Fig. 13 mainly indicate the atmospheric variability within the defined areas given in Sect. 2.5. Good agreement between the BERTHA and the CALIOP measurements is found.

A considerable part of the scatter in the BERTHA data is, however, caused by retrieval uncertainties (see the systematic uncertainty bars in Fig. 13). These uncertainties are rather large for $355 \mathrm{~nm}$. The error bars of the individual measurements only show the variability (standard deviation, SD) around the mean values within the observed individual SAL height range from base to top. The systematic errors of the $1064 \mathrm{~nm}$ particle depolarization ratio are comparably small. Thus the fluctuations of the $1064 \mathrm{~nm}$ depolarization ratio indicate the changes in the dust microphysical characteristics from day to day. The large-particle fraction is expected to vary with time as a function of varying dust removal strength due to different travel conditions across the Atlantic and different weather conditions. This especially influences the $1064 \mathrm{~nm}$ SAL mean depolarization ratio, according to the discussion below. The depolarization-ratio measurements at $1064 \mathrm{~nm}$ will improve the retrieval of microphysical properties according to Gasteiger and Freudenthaler (2014).

Table 2 provides the overall SALTRACE (summers of 2013 and 2014) mean depolarization-ratio values for all three wavelengths, the associated SD values (showing the day-today variability of the SAL), and typical systematic retrieval errors. Typical systematic errors are obtained from averaging of the respective uncertainties of the 21 evening observa- 


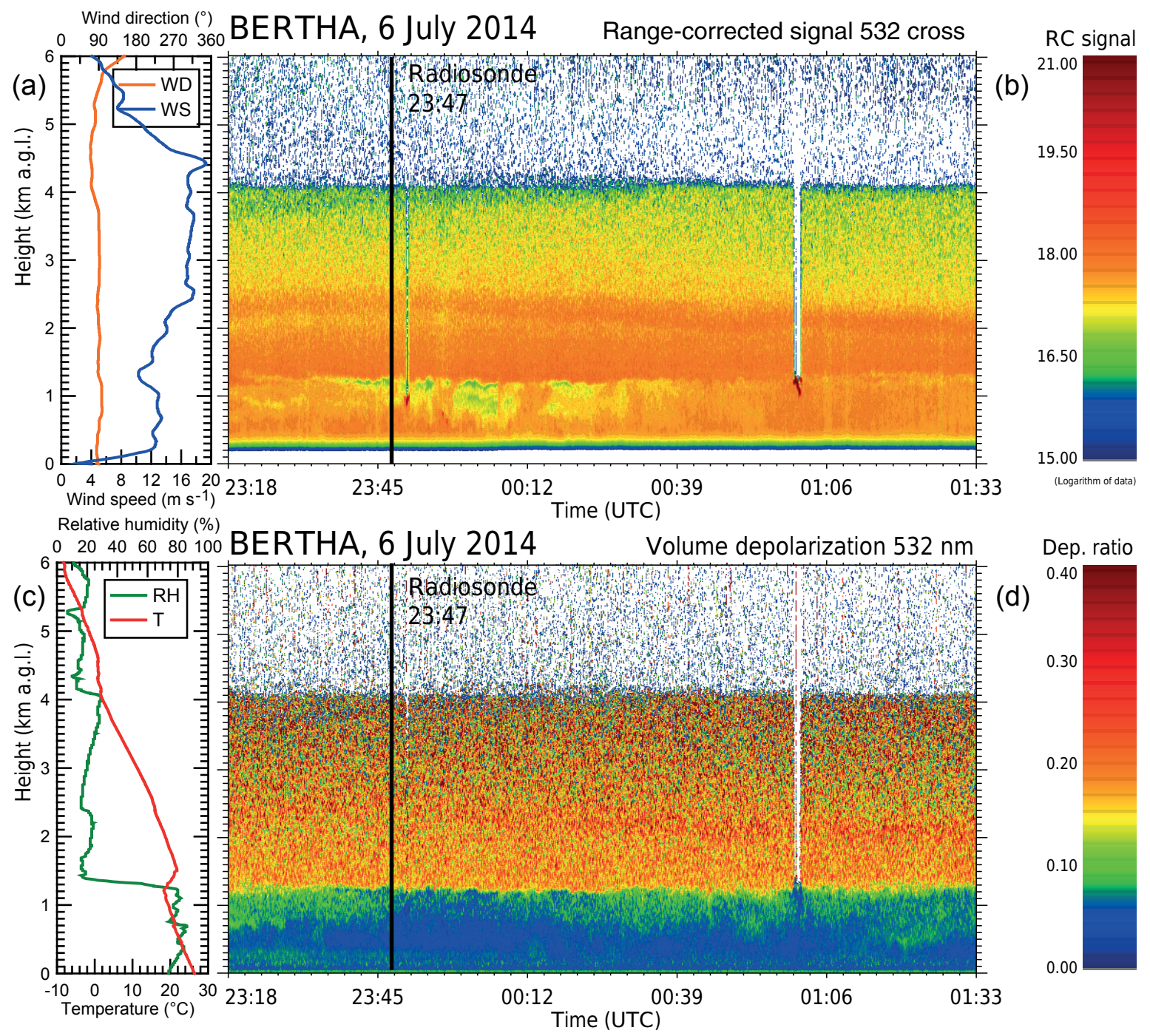

Figure 11. Saharan air layer (from 1.2 to $4.2 \mathrm{~km}$ height) above the marine boundary layer. The same parameters as in Fig. 2 are shown. The lidar observation was performed on 6 July 2014, 19:18-21:33 LT. The radiosonde was launched at 19:47 LT (indicated by a black vertical line).

tional cases. The SALTRACE mean depolarization ratios are $0.25(355 \mathrm{~nm}), 0.28(532 \mathrm{~nm})$, and $0.23(1064 \mathrm{~nm})$.

We found good agreement between the two depolarization data sets collected with POLIS (Groß et al., 2015) and BERTHA for July 2013. On average, particle depolarization ratios were 0.28 (POLIS) and 0.29 (BERTHA) at $532 \mathrm{~nm}$ and 0.27 (POLIS) and 0.26 (BERTHA) at $355 \mathrm{~nm}$. For June 2013, the results at $532 \mathrm{~nm}$ differ significantly. On average, we observed with BERTHA June 2013 means of $0.26(532 \mathrm{~nm})$ and $0.26(355 \mathrm{~nm})$ based on four individual evening measurements. The POLIS June 2013 mean values (based on three evening measurement sessions) were higher at $532 \mathrm{~nm}$ $(0.29)$ and equal at $355 \mathrm{~nm}(0.26)$. The large systematic uncertainties in the BERTHA depolarization ratios are probably mainly responsible for the observed differences as well as the low number of observations.
Table 2. SALTRACE mean particle linear depolarization ratio and corresponding standard deviation (SD), for all three wavelengths, observed within the Saharan dust layer with BERTHA in June and July 2013 and June and July 2014 (21 cases). Typical uncertainties in the retrieval of individual particle depolarization-ratio values (systematic errors, Sys. error) are given for comparison. These uncertainties consider the volume depolarization retrieval uncertainties (see Appendix) and uncertainties in the backscatter coefficients required as input in addition.

\begin{tabular}{lrrr}
\hline Wavelength & Mean & SD & Sys. error \\
\hline $355 \mathrm{~nm}$ & 0.252 & 0.030 & 0.074 \\
$532 \mathrm{~nm}$ & 0.280 & 0.020 & 0.019 \\
$1064 \mathrm{~nm}$ & 0.225 & 0.022 & 0.008 \\
\hline
\end{tabular}




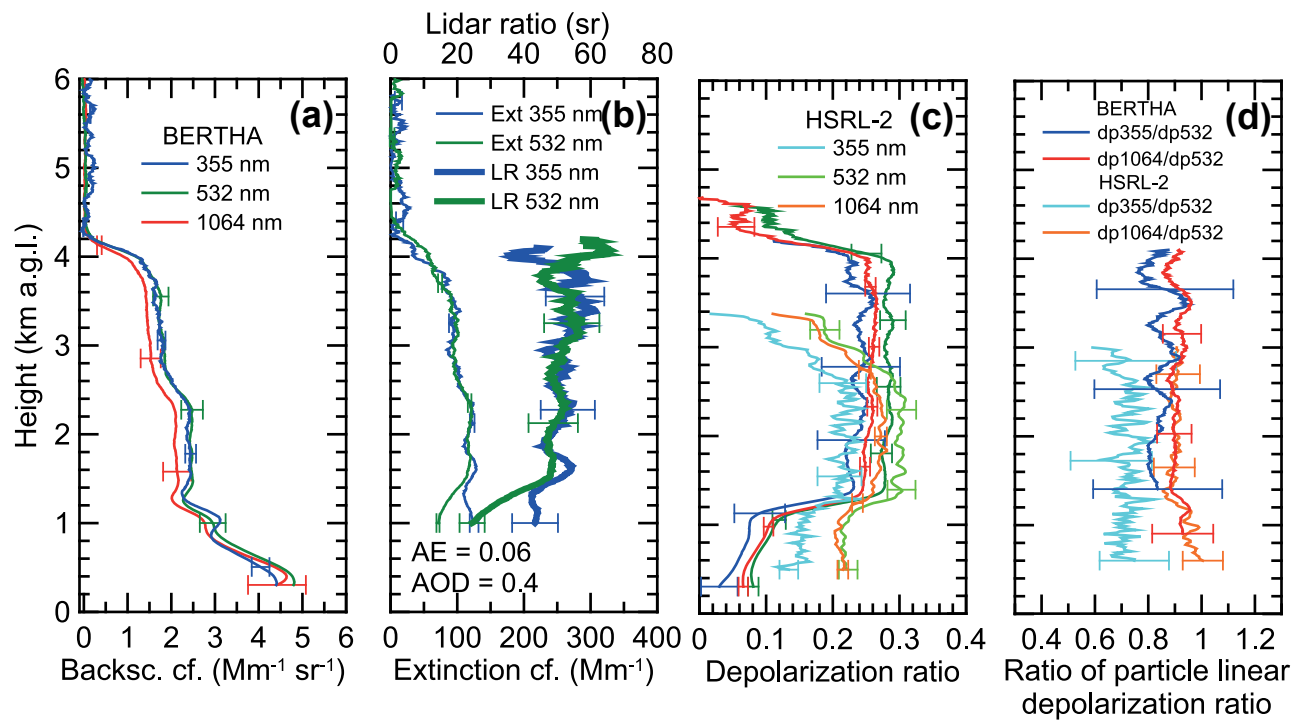

Figure 12. Same as Fig. 9, except for 6-7 July 2014, 23:18-01:33 UTC. For comparison, respective height profiles of the particle linear depolarization ratio (355 $\mathrm{nm}$ in light blue, $532 \mathrm{~nm}$ in light green, and $1064 \mathrm{~nm}$ in orange) and for the ratio of depolarization ratios (in light blue and orange) measured with an airborne triple-wavelength polarization lidar (HSRL-2) (Burton et al., 2015) on 13 July 2014, 17:00 UTC are shown. The airborne lidar observations were performed in Missouri (midwestern United States), about $7000 \mathrm{~km}$ and 7 days downwind of Barbados.

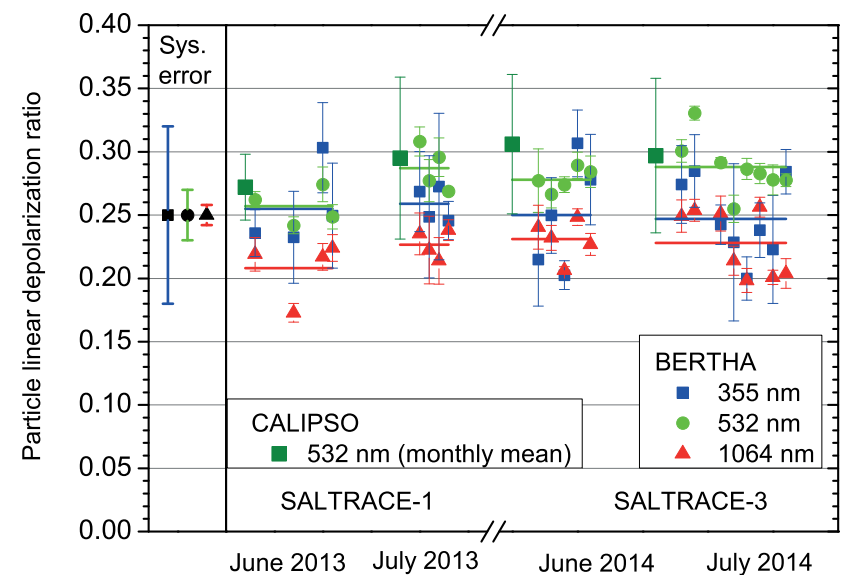

Figure 13. Overview of SAL layer mean particle depolarization ratios measured with triple-wavelength polarization lidar BERTHA during SALTRACE-1 (2013) and SALTRACE-3 (2014). Only triple-wavelength observations (one per evening) are considered. Horizontal lines show the mean values of all measurements conducted in 1 of the 4 SALTRACE months in 2013 and 2014. Error bars indicated the standard deviation calculated from all depolarization values (available with $50 \mathrm{~m}$ vertical resolution) between SAL base and top. Respective CALIOP monthly mean values and standard deviations of the SAL column particle depolarization ratios at $532 \mathrm{~nm}$ are shown for comparison. Level 2 version 3.30 CALIPSO aerosol profile data around Barbados are used for this retrieval (CALIPSO, 2016). The systematic error bars shown on the left-hand side illustrate the impact of all the retrieval uncertainties on the results.

\section{Discussion}

Figure 14 provides an overview of the entire SAMUMSALTRACE data set of depolarization ratios collected from 2006 to 2014 in southeastern Morocco (SAMUM1), at Praia in Cabo Verde (SAMUM-2), and on Barbados (SALTRACE). There is almost no change of the mean $355 \mathrm{~nm}$ and $532 \mathrm{~nm}$ particle depolarization ratio with distance from the dust source when combining the BERTHA (Barbados) and POLIS-MULIS (Cabo Verde, Morocco) data sets. The POLIS-MULIS data sets indicate a slow decrease of the mean $532 \mathrm{~nm}$ depolarization value from 0.31 (Morocco) to 0.30 (Cabo Verde) to 0.28 (Barbados), but the difference is not significant. The available $1064 \mathrm{~nm}$ mean values indicate a significant decrease from a Morocco mean value of 0.27 to a Barbados mean value of 0.23 . We speculate that a large fraction of large dust particles causing depolarization ratios of 0.40 is present over areas close to the Sahara but that these large particles are strongly removed before reaching Barbados. The other two wavelengths ( 355 and $532 \mathrm{~nm}$ ) are more sensitive to fine-mode dust (accumulation-mode particles with diameters $<1 \mu \mathrm{m}$ ), for which the removal by gravitational settling is less efficient. In particular, the $355 \mathrm{~nm}$ SAL values, widely controlled by fine-mode dust particles, show rather robust behavior. No trend in the $355 \mathrm{~nm}$ depolarization values is observed in the SAMUM-1, SAMUM-2, and SALTRACE data.

Figure 14 includes CALIOP depolarization measurements performed in the Morocco, Cabo Verde, and Barbados regions in June and July of 2013 and 2014. The overall 4- 


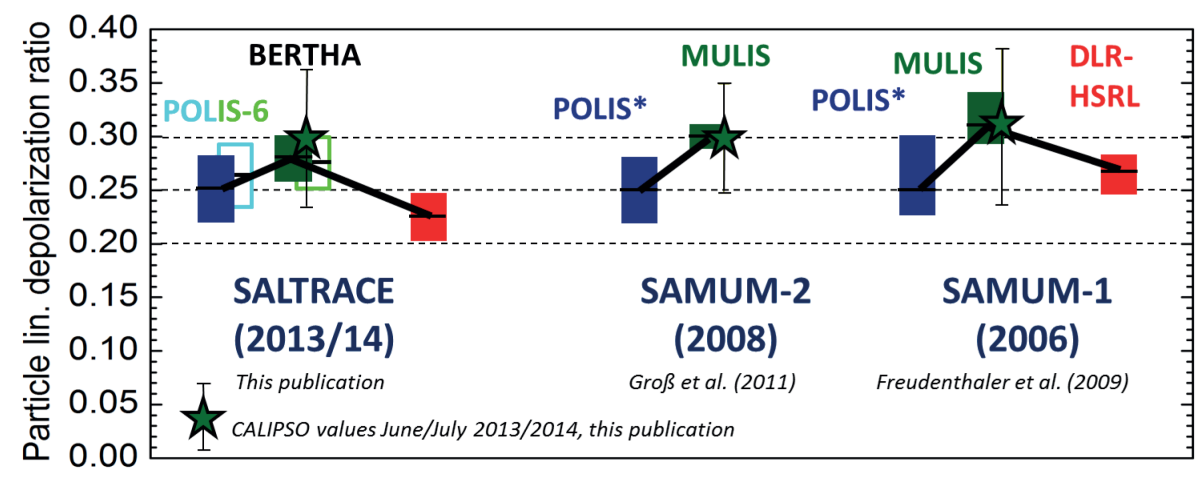

Figure 14. Comparison of dust-layer mean particle linear depolarization ratios measured during SAMUM-1 (Morocco), SAMUM-2 (Cabo Verde), and SALTRACE (Barbados). Colored bars show the range of mostly observed depolarization ratios at $355 \mathrm{~nm}$ (blue), $532 \mathrm{~nm}$ (green), and $1064 \mathrm{~nm}$ (red). The lidars BERTHA, POLIS, and MULIS (the second polarization lidar of Munich University) and the airborne highspectral-resolution lidar (HSRL) of DLR (Deutsches Zentrum für Luft- und Raumfahrt) were used to collect this data set. Data are taken from the publications of Freudenthaler et al. (2009, SAMUM-1, 19 cases for MULIS, 2-4 cases for the other systems), Groß et al. (2011a, SAMUM-2, 9 cases for POLIS, 5 cases for MULIS), Groß et al. (2015, SALTRACE, POLIS-6), and from this study (21 cases). In addition, CALIOP mean values of SAL column depolarization ratios considering all observations during the 4 SALTRACE months (June and July in 2013 and 2014) are shown. The mean values consider all CALIOP overpasses of selected areas in southeastern Morocco, in the Cabo Verde region, and around Barbados during these 4 months.

month mean values (plus SD) are shown. The CALIOP $532 \mathrm{~nm}$ mean values (and SD) are $0.31 \pm 0.07$ (Morocco), $0.30 \pm 0.05$ (Cabo Verde), and $0.30 \pm 0.06$ (Barbados). Good agreement between the ground-based BERTHA and spaceborne CALIOP observations is obtained, and no significant trend in the $532 \mathrm{~nm}$ particle depolarization ratio found. Veselovskii et al. (2016) reported average $532 \mathrm{~nm}$ particle linear depolarization ratios of $0.30 \pm 0.045$ for the SHADOW campaign in Senegal during dust outbreaks in March-April 2015.

The spectral slope of the depolarization ratio, shown in Fig. 15, with the maximum at $532 \mathrm{~nm}$ and lower values at 355 and $1064 \mathrm{~nm}$, reflects the different influence of the fine-mode and coarse-mode dust fractions on the overall (fine + coarse) particle depolarization ratio at the three wavelengths. The $355 \mathrm{~nm}$ dust particle depolarization ratio is strongly influenced by fine-mode dust (up to 50-60\% fine mode fraction (FMF) according to AERONET observations). Fine-mode dust causes a depolarization ratio around 0.20 at $355 \mathrm{~nm}$. The comparably weak influence of coarse-mode dust (causing depolarization ratios $>0.30$ ) leads to an overall (fine + coarsemode) particle linear depolarization ratio of $0.25 \pm 0.03$. The $532 \mathrm{~nm}$ dust depolarization ratio is still sensitively influenced by fine-mode dust (FMF 10-30\% contribution, causing a fine-mode depolarization ratio around 0.15 ) but also by the coarse-mode dust particle fraction (leading to a depolarization ratio of $0.35-0.40$ ). The overall effect of fine-mode and coarse-mode depolarization then leads to the observed $532 \mathrm{~nm}$ depolarization ratios around $0.28-0.30$. In contrast, about $95 \%$ of the $1064 \mathrm{~nm}$ dust particle depolarization ratio is caused by coarse-mode dust particles (FMF $5 \%$ ), according to AERONET observations, and seems to be between

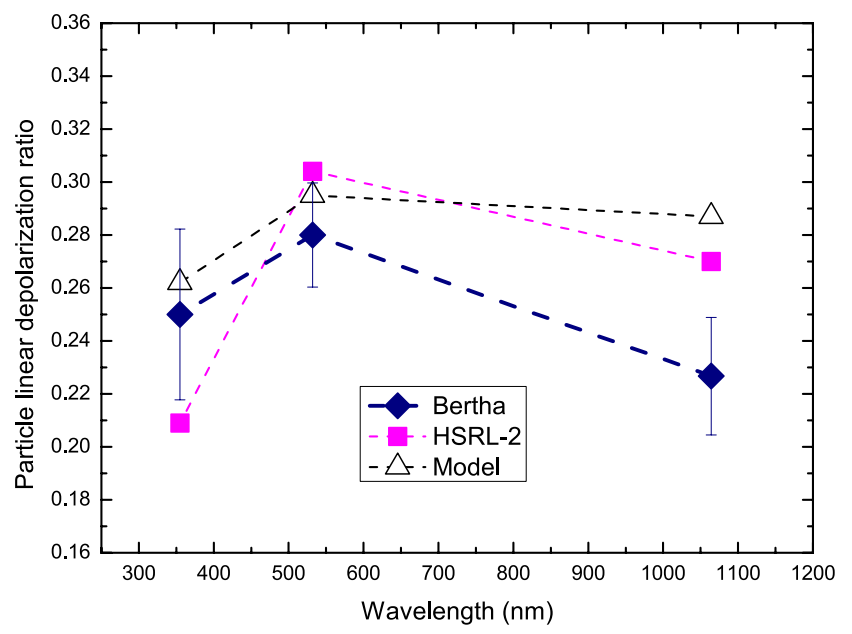

Figure 15. SALTRACE mean dust particle linear depolarization ratios at 355, 532, and $1064 \mathrm{~nm}$ (SAL column mean values and corresponding standard deviations) measured with BERTHA (21 cases). In addition, the HSRL-2 observation (Burton et al., 2015) discussed in Sect. 3.3 is shown. The observational findings are compared with respective model results, which are based on the dust size-shape characteristics described in Gasteiger et al. (2017).

0.20 and 0.28 for dust after long-range transport. The influence of the fine- and coarse-mode dust fractions on the particle linear depolarization ratio is discussed in detail by Mamouri and Ansmann (2017).

Simulation studies of Kemppinen et al. (2015a) can be used to interpret our depolarization observations. These simulations are based on realistic dust particle shapes, measured during SAMUM-1 in Morocco (Lindqvist et al., 2014). 
For the so-called dolomite shape type, the simulations yield 1064 and $532 \mathrm{~nm}$ coarse-mode particle linear depolarization ratios of $0.20-0.25$ and $0.35-0.40$, respectively, provided dust particles with diameters around $1.5-2.0 \mu \mathrm{m}$ dominate backscattering of laser photons. These depolarization values are in good agreement with the $1064 \mathrm{~nm}$ lidar observations as well as with $532 \mathrm{~nm}$ depolarization studies when taking a dust fine-mode fraction of $20 \%$ (as indicated by AERONET sun photometer observations), a fine-mode depolarization ratio of 0.15 , and a measured $532 \mathrm{~nm}$ depolarization ratio of 0.30 into account, as explained in detail by Mamouri and Ansmann (2017). It is interesting to note in this context that the AERONET photometer observations during dust outbreaks over Barbados in 2013 and 2014 show that the coarse-mode effective diameter accumulates around $3 \pm 0.4 \mu \mathrm{m}$, which indicates that most coarse-mode dust particles after long-range transport have diameters in the 1-3 $\mu \mathrm{m}$ size range. Veselovskii et al. (2016) retrieved overall (finemode + coarse-mode) effective diameters of 2-2.5 $\mu \mathrm{m}$ from the multiwavelength lidar measurements in the dust plumes over Senegal during the SHADOW campaign.

This consistency between the lidar observations, photometer retrievals, and simulation studies is promising and suggests that our triple-wavelength polarization lidar observations are very useful for the next steps in dust simulation studies with the goal of developing an appropriate dust sizeshape parametrization scheme for atmospheric weather and climate models. However, the consistency created here is not more than an hypothesis. Many more laboratory and model studies, together with our complex field observations, are required to improve stepwise our knowledge on the complex relationship between fundamental dust properties and related optical effects.

Figure 15 provides a comparison of the observations with triple-wavelength polarization lidars (BERTHA, HSRL-2) and a preliminary modeling result of the depolarization ratios described by Gasteiger et al. (2017) in their hypothesis with vertical mixing during the day. A mix of irregularly shaped (non-spheroidal) particles and small spherical ammonium sulfate particles is assumed in the simulation. The mineralogical variability is mimicked by mixing of absorbing and non-absorbing particles. The spectral trend observed with the lidars is also visible in the simulation. The deviation of the modeled spectral slope of the depolarization ratio from the observed wavelength dependence may be related to the shape parametrization of the rough estimate of the dust size distribution. Figure 15 may be regarded as the starting point of a comprehensive modeling effort. Dense observational data on depolarization ratios together with airborne in situ observations of size distributions and the mineralogical and chemical composition of the dust particles in the Barbados region (Weinzierl et al., 2017) are now available for in-depth simulation studies of dust optical properties.

\section{Conclusions}

Triple-wavelength polarization lidar measurements in longrange transported Saharan dust layers were performed in Barbados, $5000-8000 \mathrm{~km}$ west of the Saharan dust sources, in the framework of three SALTRACE campaigns, each lasting several weeks. High quality was achieved by comparing the BERTHA observations with depolarization-ratio profiles measured with a reference system and by using cirrus layers in which the spectral dependence of the particle depolarization ratio vanishes. A unique case of long-range-transported dust over more than $12000 \mathrm{~km}$ was presented and indicated widely unchanged Saharan dust optical properties even after a travel time of 2 weeks since the emission. On average, the particle linear depolarization ratios for aged Saharan dust were found to be $0.252 \pm 0.030$ at $355 \mathrm{~nm}, 0.280 \pm 0.020$ at $532 \mathrm{~nm}$, and $0.225 \pm 0.022$ at $1064 \mathrm{~nm}$ (mean \pm standard deviation). According to published simulation studies we conclude that most of the coarse-mode dust particles have sizes around $2 \mu \mathrm{m}$ in diameter after 1 week of travel. By comparing the SALTRACE results to the SAMUM-1 and SAMUM2 results, again, only minor changes in the dust depolarization characteristics were observed on the way from the $\mathrm{Sa}$ haran dust sources towards the Caribbean. Only the $1064 \mathrm{~nm}$ depolarization-ratio mean value decreased significantly from Morocco towards the Caribbean.

A long-term data set of the particle linear depolarization ratio of mineral dust measured simultaneously at 355,532 , and $1064 \mathrm{~nm}$ is now available. In addition, dense 355 and $532 \mathrm{~nm}$ lidar ratio data sets are available (Groß et al., 2011a, 2015; Tesche et al., 2011a). Furthermore, airborne in situ observations of the dust particle size distribution and chemical composition in the SAL are available (Weinzierl et al., 2017). This is an excellent basis for comprehensive simulation efforts to develop realistic dust shape models and parametrization schemes which link the dust size distribution, composition, and shape characteristics with the resulting optical and radiative properties of mineral dust particles.

The available coherent multiwavelength data sets on linear depolarization ratios and lidar ratios (from the source region to remote areas of long-range transport) support present and upcoming spaceborne lidar missions (CALIPSO and EarthCARE missions) and the development of new space lidar mission concepts (based on multiwavelength polarization or HSRL lidar missions). They can further be used to harmonize existing and future depolarization data sets collected at different lidar wavelengths. Furthermore, existing dust retrieval schemes such as the technique presented in this SALTRACE special issue by Mamouri and Ansmann (2017) can be checked and improved based on the available complex depolarization-ratio data sets.

Together with the observations of the 355 and $532 \mathrm{~nm}$ depolarization ratios with POLIS (EARLINET reference system), a high-quality data set on depolarization ratios at 355 , 532, and $1064 \mathrm{~nm}$ for Saharan dust after long-range transport 
is now available for the first time. Comparison with another triple-wavelength depolarization-ratio data set indicates that the Barbados data are very trustworthy. CALIOP depolarization ratios collected over the SAMUM-1, SAMUM-2, and the SALTRACE field sites are in very good agreement with the findings of the ground-based lidars. Altogether, a significant dust aging effect, triggering a significant change of the dust depolarization ratio from regions close to the source to areas more than $5000 \mathrm{~km}$ downwind, is not visible in the observations. Discrepancies between the modeled and the observed depolarization ratios are not surprising when keeping in consideration that the shape characteristics of the irregularly shaped dust particles are not well known, and a realistic shape model is not existing.
As an outlook, we are presently testing to measure not only dust depolarization ratios at three wavelengths but also the dust extinction coefficient at these three wavelengths. First test observations were promising (Haarig et al., 2016b).

Data availability. HYSPLIT backward trajectories are calculated via the available simulation tools (HYSPLIT, 2016). AERONET sun photometer AOT data were downloaded from the AERONET web page (AERONET, 2016). SALTRACE BERTHA lidar data are available at TROPOS. CALIOP signal profile data are made available by the CALIPSO science team (CALIPSO, 2016). We used level 2 version 3.30 CALIPSO Aerosol profile data. 


\section{Appendix A: Polarization channels and their calibration in the lidar system BERTHA}

The Appendix A briefly explains the state-of-the-art concept of polarization lidar according to Freudenthaler (2016) and discusses some special features of the BERTHA lidar system. In the second part, the BERTHA lidar system will be characterized in detail and the systematic errors will be estimated.

\section{A1 Calculation of the depolarization ratio}

In a state-of-the-art approach, the components of the lidar system are described by Mueller matrices using the MuellerStokes formalism (Freudenthaler, 2016):

$$
\begin{aligned}
\boldsymbol{I}_{\mathrm{S}}= & \eta_{\mathrm{S}} \mathbf{M}_{\mathrm{S}}\left(D_{\mathrm{S}}, \nu_{\mathrm{S}}, \Delta_{\mathrm{S}}\right) \mathbf{C}(\Psi, \epsilon) \mathbf{M}_{0}\left(D_{0}, \gamma, \Delta_{0}, a_{0}\right) \\
& \mathbf{F}(a) \mathbf{M}_{\mathrm{E}}\left(D_{\mathrm{E}}, \beta, \Delta_{\mathrm{E}}, a_{\mathrm{BE}}\right) \boldsymbol{I}_{\mathrm{L}}(\alpha) .
\end{aligned}
$$

The different quantities have to be known, or at least good estimates and their uncertainties are needed. They will be described in the following text and determined for each wavelength separately in the next section. An overview is given in Table A1.

All the rotational misalignment around the optical axis (rotational misalignment in the following) is expressed with respect to the plane of polarization of the polarization filter in front of the PMT, belonging to the cross-polarized channel of the corresponding wavelength. The emitted laser light $\boldsymbol{I}_{\mathrm{L}}$ has a rotational misalignment $\alpha$.

The emitting optics $\mathbf{M}_{\mathrm{E}}$ (beam expander and steering mirrors) have a diattenuation parameter (called diattenuation in the following) $D_{\mathrm{E}}$, a retardation $\Delta_{\mathrm{E}}$, and a misalignment $\beta$. Furthermore the beam expander may cause depolarization due to inhomogeneities over its surface and birefringence of the calcium fluoride lens. The degree of linear polarization after the beam expander is given by $a_{\mathrm{BE}}$.

F represents the scattering process in the atmosphere with an atmospheric polarization parameter $a$ corresponding to the atmospheric volume linear depolarization ratio $\delta_{\mathrm{v}}$ :

$a=\frac{1-\delta_{\mathrm{V}}}{1+\delta_{\mathrm{V}}}$,

which is the unknown quantity that will be derived by polarization lidar measurements

The receiving optics $\mathbf{M}_{0}$ (in the case of BERTHA only the telescope and a $90^{\circ}$ mirror) are characterized by the diattenuation $D_{0}$, the retardation $\Delta_{0}$, and the misalignment $\gamma$.

A linear polarizer is used for the calibration $\mathbf{C}$, the position $\Psi$ is +45 or $-45^{\circ}$, and $\epsilon$ is the deviation of this ideal position, but does not affect the exact $90^{\circ}$ angle between the two calibration positions $\left( \pm 45^{\circ}\right)$. The exact difference is reached by a highly accurate $\left(10^{-4 \circ}\right)$ step motor (8SMC1 from Standa Ltd., Lithuania). The calibrator is only used during the calibration measurements. For the regular measure- ments, it is taken out of the beam, and therefore a possible misalignment is not affecting the measurements.

The detection units for the total channel (index $\mathrm{S}=\mathrm{T}$ ) and for the cross-polarized channel (index $S=R$ ), $\mathbf{M}_{T}$ and $\mathbf{M}_{R}$, include a diattenuation, which would be ideally $D_{\mathrm{T}}=0$ and $D_{\mathrm{R}}=-1$. In addition to Freudenthaler (2016) a rotational misalignment $v_{\mathrm{S}}$ and a retardation $\Delta_{\mathrm{S}}$ have to be included in the formulas for the BERTHA lidar system. The calibrator is located behind the telescope and before the beam separation unit (see Fig. 1). The retardation $\Delta_{S}$ has no effect on the measured intensity and needs no further consideration. For the total channel there is no rotational misalignment; only $v_{\mathrm{R}}$ for the cross-polarized channel has to be taken into account. The gain ratios of the PMTs and their neutral density filters are represented by $\eta_{\mathrm{T}}$ and $\eta_{\mathrm{R}}$, respectively. A calibration measurement for every change in the neutral density filters was performed.

Freudenthaler (2016) presents a solution to the matrix equation (Eq. A1), introducing the parameters $G_{\mathrm{S}}$ and $H_{\mathrm{S}}$ as system constants. They are a simplification in the notation of the solution and depend on all previously mentioned system parameters (Table A1). The remaining unknown is the atmospheric polarization parameter $a$. The intensity (first component of the Stokes vector $\boldsymbol{I}_{\mathrm{S}}$ ) is given by the following:

$I_{\mathrm{S}}=\eta_{\mathrm{S}} T_{\mathrm{S}} T_{0} F_{11} T_{\mathrm{E}} I_{\mathrm{L}}\left(G_{\mathrm{S}}+a H_{\mathrm{S}}\right)$,

with the laser intensity $I_{\mathrm{L}}$, the transmittance of the emitting optics $T_{\mathrm{E}}$ of the receiving optics $T_{0}$ of the detection unit $T_{\mathrm{S}}$, the backscatter coefficient $F_{11}$, and the gain of the detector $\eta_{\mathrm{S}}$. Taking the ratio of two signals (cross, index $\mathrm{S}=\mathrm{R}$, and total, index $\mathrm{S}=\mathrm{T}$ ), only $T_{\mathrm{S}}$ and $\eta_{\mathrm{S}}$ are remaining. The volume linear depolarization ratio $\delta_{\mathrm{v}}$ can be determined as follows.

$\delta_{\mathrm{v}}=\frac{\delta^{*}\left(G_{\mathrm{T}}+H_{\mathrm{T}}\right)-\left(G_{\mathrm{R}}+H_{\mathrm{R}}\right)}{\left(G_{\mathrm{R}}-H_{\mathrm{R}}\right)-\delta^{*}\left(G_{\mathrm{T}}-H_{\mathrm{T}}\right)}$

with the calibrated signal ratio $\delta^{*}$ :

$\delta^{*}=\frac{1}{\eta} \frac{I_{\mathrm{R}}}{I_{\mathrm{T}}}$,

with calibration factor $\eta$, determined by the $\Delta 90^{\circ}$-calibration (Freudenthaler et al., 2009). The measured calibration factor $\eta^{*}$ has to be corrected for any of the above-mentioned rotational misalignment. The correction constant $K$ is used to obtain the calibration factor $\eta$ (Freudenthaler, 2016)

$\eta=\frac{\eta^{*}}{K}$

The five parameters $G_{\mathrm{T}}, H_{\mathrm{T}}, G_{\mathrm{R}}, H_{\mathrm{R}}$, and $K$ (system constants) are calculated from the system characteristics (Table A1) for each wavelength. 
Table A1. BERTHA parameters (values) used in the volume depolarization-ratio retrieval and uncertainties. Each wavelength is treated separately: rotational misalignment of the laser $(\alpha)$, the emitting optics $(\beta)$, the receiving optics $(\gamma)$, and the cross-polarized receiver channel $\left(v_{\mathrm{R}}\right)$; diattenuation and retardation of the emitter optics $\left(D_{\mathrm{E}}, \Delta_{\mathrm{E}}\right)$ and the receiver optics $\left(D_{0}, \Delta_{0}\right)$; the diattenuation of the total and crosspolarized receiver channel $\left(D_{\mathrm{T}}, D_{\mathrm{R}}\right)$; the degree of linear polarization of the beam expander $\left(a_{\mathrm{BE}}\right)$ and the polarization parameter of the $90^{\circ}$ mirror in the telescope $\left(a_{0}\right)$. Explanations for the parameters are given in the text. The configuration is given for SALTRACE-3 (summer 2014).

\begin{tabular}{lrr|rr|rr}
\hline \multirow{2}{*}{ Property } & \multicolumn{2}{c|}{$355 \mathrm{~nm}$} & \multicolumn{2}{c|}{$532 \mathrm{~nm}$} & \multicolumn{2}{c}{$1064 \mathrm{~nm}$} \\
\cline { 2 - 7 } & Value & Uncertainty & Value & Uncertainty & Value & Uncertainty \\
\hline$\alpha$ & $0.9^{\circ}$ & $\pm 0.2^{\circ}$ & $1.1^{\circ}$ & $\pm 0.1^{\circ}$ & $0.9^{\circ}$ & $\pm 0.2^{\circ}$ \\
$D_{\mathrm{E}}$ & 0.049 & \pm 0.034 & 0.046 & \pm 0.028 & 0.047 & \pm 0.037 \\
$\Delta_{\mathrm{E}}$ & $0^{\circ}$ & $\pm 180^{\circ}$ & $0^{\circ}$ & $\pm 180^{\circ}$ & $0^{\circ}$ & $\pm 180^{\circ}$ \\
$\beta$ & $0^{\circ}$ & $\pm 1^{\circ}$ & $0^{\circ}$ & $\pm 1^{\circ}$ & $0^{\circ}$ & $\pm 1^{\circ}$ \\
$a_{\mathrm{BE}}$ & 0.97 & \pm 0.02 & 1.00 & -0.01 & 1.00 & -0.01 \\
$D_{0}$ & 0.07 & \pm 0.02 & -0.057 & \pm 0.005 & 0.040 & \pm 0.01 \\
$\Delta_{0}$ & $0^{\circ}$ & $\pm 180^{\circ}$ & $0^{\circ}$ & $\pm 180^{\circ}$ & $0^{\circ}$ & $\pm 180^{\circ}$ \\
$\gamma$ & $0^{\circ}$ & $\pm 0.2^{\circ}$ & $0^{\circ}$ & $\pm 0.2^{\circ}$ & $0^{\circ}$ & $\pm 0.2^{\circ}$ \\
$a_{0}$ & 1.00 & -0.01 & 0.958 & \pm 0.005 & 1.00 & -0.01 \\
$D_{\mathrm{T}}$ & 0.07 & \pm 0.01 & 0.088 & \pm 0.01 & 0.080 & \pm 0.01 \\
$D_{\mathrm{R}}$ & -0.903 & \pm 0.01 & -0.992 & \pm 0.01 & -0.980 & \pm 0.01 \\
$\nu_{\mathrm{R}}$ & $0^{\circ}$ & $\pm 0.5^{\circ}$ & $0^{\circ}$ & $\pm 0.5^{\circ}$ & $0^{\circ}$ & $\pm 0.5^{\circ}$ \\
\hline
\end{tabular}

Table A2. The results of the simulation of the lidar system for the volume linear depolarization ratio. The simulation has been performed for the theoretical Rayleigh background and a typical value for the dust layer for each wavelength. The maximum and minimum value for each simulation and its standard deviation is given.

\begin{tabular}{lrrrr|rrrrr}
\hline \multirow{2}{*}{ Wavelength } & \multicolumn{4}{c|}{ Rayleigh } & \multicolumn{4}{c}{ Dust layer } \\
\cline { 2 - 9 } & input & min. & max. & SD & input & min. & max. & SD \\
\hline $355 \mathrm{~nm}$ & 0.0080 & -0.0130 & 0.0440 & 0.0100 & 0.080 & 0.056 & 0.118 & 0.010 \\
$532 \mathrm{~nm}$ & 0.0053 & -0.0020 & 0.0260 & 0.0049 & 0.200 & 0.188 & 0.224 & 0.006 \\
$1064 \mathrm{~nm}$ & 0.0036 & -0.0050 & 0.0250 & 0.0057 & 0.230 & 0.214 & 0.257 & 0.007 \\
\hline
\end{tabular}

\section{A2 System characterization}

The results of the system characterization are shown in Table A1. Similar characterizations of different EARLINET lidars have been reported by Bravo-Aranda et al. (2016). The results are shown for the conditions during SALTRACE-3 as it was characterized when the system was back in Leipzig. Some characterization and optimization efforts have already been done at the field site in Barbados. Being exposed for 1 year to tropical conditions (high temperature and humidity) and the transport from Barbados to Leipzig might have an influence on the system characteristics, which is hard to quantify.

The degree of linear polarization of the laser is high (>95\% according to the manufacturer's specification) and it is additionally cleaned by a Glan-Taylor polarizer, whose misalignment with respect to the optical table is characterized by the angle $\alpha$ and measured with the help of an additional polarization filter with the uncertainty of $0.2^{\circ}$.

The beam expander is the major source of uncertainty in the emitter optics, as it has to deal with the three wavelengths simultaneously and the high power of the laser. The CaFl lens used appears to be birefringent. In order to check this issue, the beam expander was tested in the EARLINET lidar calibration center in Bucharest (http://www.lical.inoe.ro). The Mueller matrix elements have been measured with transmission ellipsometry at 25 points over the surface of the beam expander. Inhomogeneities of the Mueller matrix elements in the external regions of the beam expander have been found, especially in the UV. As a first approximation a degree of linear polarization of $0.97 \pm 0.02$ in the UV after the beam expander is assumed. In the visible and near infrared the degree of linear polarization is almost ideal (0.99 to 1.00$)$. The influence of the other components (mainly steering mirrors) on the emitter optics is neglected so far, although the diattenuation of the emitter optics is mainly induced by these steering mirrors. From the transmission ellipsometry of the beam expander a diattenuation $\left(D_{\mathrm{E}}\right)$ smaller than 0.05 is derived. Not all elements of the Mueller matrix of the beam expander could be measured. Therefore the retardation $\Delta_{\mathrm{E}}$ of the emitter optics is not known, and the maximum uncertainty of $\pm 180^{\circ}$ is assumed. The same assumption has been made for 

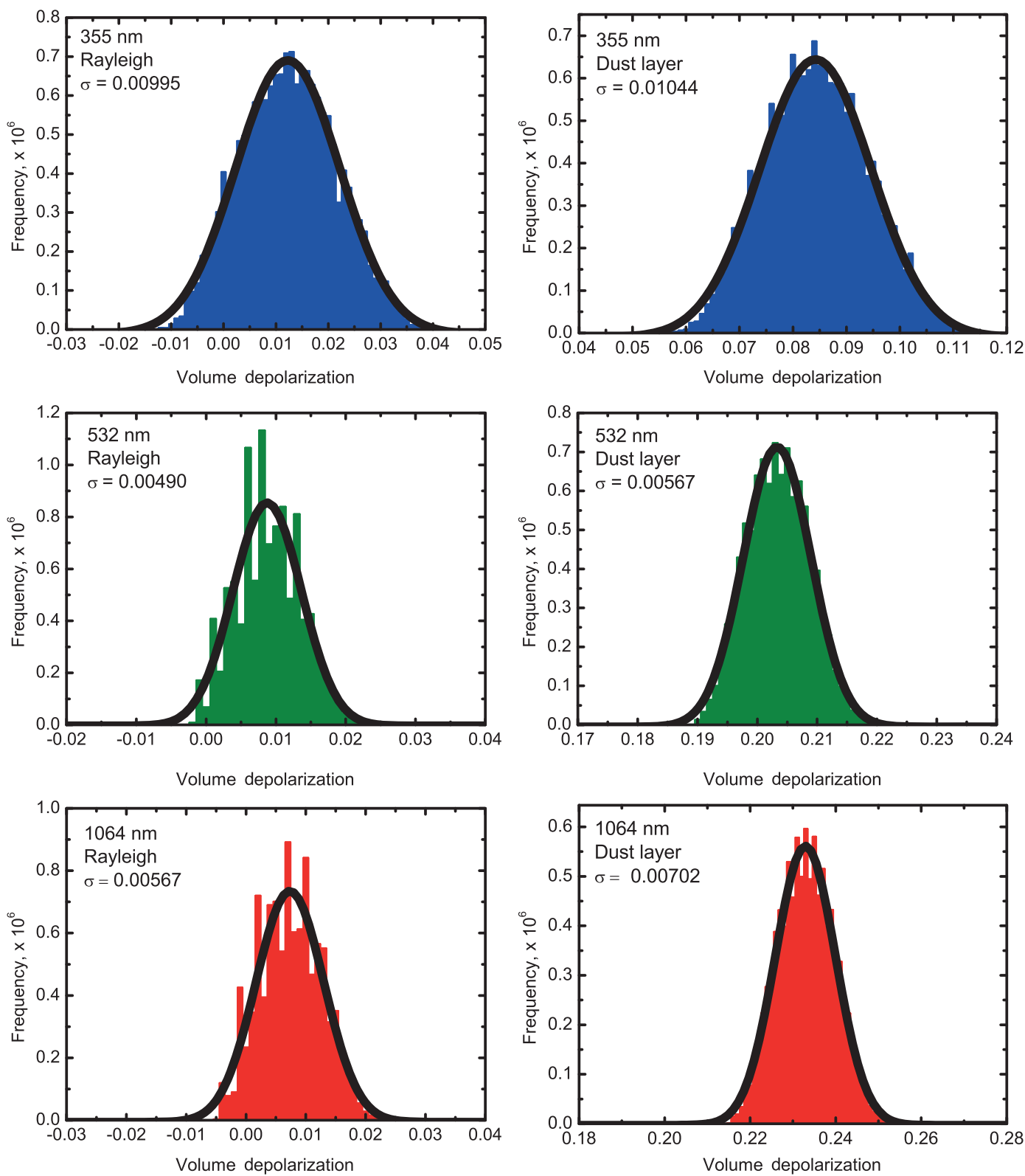

Figure A1. Frequency distribution (in millions of individual computations) of the volume depolarization ratio derived by a Monte Carlo simulation of the system parameters of the BERTHA lidar system (Table A1) within their uncertainties. For each wavelength the Rayleigh depolarization and a typical value in the dust layer was chosen as the input value (true value), given in Table A2. The standard deviation $\sigma$ of the Gaussian fit (black line) is given to estimate the error of the volume depolarization ratio.

other EARLINET lidars by Bravo-Aranda et al. (2016). An appropriate assumption for the rotational misalignment $\beta$ is $0^{\circ} \pm 1.0^{\circ}$.

The receiver diattenuation $\left(D_{0}, D_{\mathrm{T}}, D_{\mathrm{R}}\right)$ was characterized using an additional light source with a known state of polarization $\left(0\right.$ to $360^{\circ}$ in steps of $\left.1^{\circ}\right)$ similar to Mattis et al. (2009). A second calibration measurement was performed with the internal linear polarizer after the telescope to separate the influence of $D_{0}$ from $D_{\mathrm{T}}$ and $D_{\mathrm{R}}$. The two calibrations indicated a depolarization of the $90^{\circ}$ mirror after the secondary mirror (see Fig. 1). The polarization parameter $a_{0}$ of this mirror has a significant influence at $532 \mathrm{~nm}$ only $\left(a_{0}=0.958\right)$. For the UV $\left(a_{0}>0.994\right)$ and the near infrared $\left(a_{0}>0.994\right)$ it can be attributed to uncertainties in the measurement $( \pm 0.005)$ and its influence is thus neglected, but considered in the error estimation. The rotational misalignment $\gamma$ of the receiving optics is assumed to be $0^{\circ} \pm 0.2^{\circ}$. It is a fixed, well-aligned system. The retardation of the receiver could not be measured, which lead to the maximum uncertainty of $\pm 180^{\circ}$. The rotational misalignment $\left(v_{R}\right)$ in 
the cross-polarized channel after the calibrator is assumed to be $0^{\circ} \pm 0.5^{\circ}$.

The deviation of the ideal calibration position $\epsilon$ can be estimated according to Freudenthaler (2016) and is only present during calibration measurements, while at the normal measurements the linear polarizer is taken out of the optical path. It varies between -3.1 and $1.8^{\circ}$ at $355 \mathrm{~nm},-2.4$ and $1.5^{\circ}$ at $532 \mathrm{~nm}$, and -1.1 and $2.4^{\circ}$ at $1064 \mathrm{~nm}$. The parameter $K$ corrects the calibration constant for the misalignment $\epsilon$. For each calibration the parameter $\mathrm{K}$ was calculated using the estimated $\epsilon$. The corrections are small as $|\epsilon|<5^{\circ}$.

$K$ is mainly influenced by the contrast ratio ( $=1 /$ extinction ratio) of the linear polarizer used for the calibration. The manufacturer CODIXX specifies the contrast ratios to be 1:10000 (at $355 \mathrm{~nm}$ ), 1:60000 (at $532 \mathrm{~nm}$ ), and $1: 90000$ (at $1064 \mathrm{~nm}$ ).

The 12 parameters listed in Table A1 introduce an uncertainty of the volume linear depolarization ratio. It is too complex to perform classical error propagation. Therefore a Monte Carlo simulation is used, as proposed by BravoAranda et al. (2016). This is actually a complete search over the multidimensional uncertainty space; there the 12 parameters are varied within their error margins. Uniform distributions are used as input. The rotational misalignment $(\alpha, \beta$, $\left.\gamma, v_{\mathrm{R}}\right)$ has been simulated with three input values, $x_{i}-\Delta x_{i}$, $x_{i}$, and $x_{i}+\Delta x_{i}$. The diattenuation $\left(D_{\mathrm{E}}, D_{0}, D_{\mathrm{T}}, D_{\mathrm{R}}\right)$ has been simulated with five input values, $x_{i}-\Delta x_{i}, x_{i}-0.5 \Delta x_{i}$, $x_{i}, x_{i}+0.5 \Delta x_{i}$, and $x_{i}+\Delta x_{i}$, as it is a are more sensitive parameter (Bravo-Aranda et al., 2016). The unknown retardation $\left(\Delta_{\mathrm{E}}\right.$ and $\left.\Delta_{0}\right)$ is simulated using five values as well: $-180,-90,0,90$, and $180^{\circ}$. The polarization parameter of the $90^{\circ}$ mirror in the telescope $a_{0}$ has been simulated with three values. For 355 and $1064 \mathrm{~nm}, 1.000,0.995$, and 0.990 were used. The degree of linear polarization after the beam expander $a_{\mathrm{BE}}$ has been simulated with three values for 532 and $1064 \mathrm{~nm}(1.000,0.995$, and 0.990) and five values for $355 \mathrm{~nm}$ (between 0.95 and 0.99 in steps of 0.01 ). The variation of $\epsilon$, which does not influence the calculation of $G_{\mathrm{S}}$ and $H_{\mathrm{S}}$, has not been taken into account to reduce the number of variables by a factor of 3 . In the Monte Carlo simulation over 11 million combinations are used for 532 and $1064 \mathrm{~nm}$. For $355 \mathrm{~nm}$ over 18 million combinations are used as input. The original code, based on Freudenthaler (2016), without our modifications as mentioned above, can be found at https://bitbucket.org/iannis_b/ (last accessed February 2017).
The simulation has been performed for the theoretical Rayleigh values $(0.0080,0.0053,0.0036)$ and typical values within the dust layer $(0.08,0.20,0.23)$ for 355,532 , and $1064 \mathrm{~nm}$, respectively. For an input value (true value) the program simulates the calibrated signal ratio $\delta^{*}$, varying all lidar parameters within their error margins as described above. Then it calculates the volume depolarization ratio $\delta_{\mathrm{v}}$ according to Eq. (A4). The frequency distributions of the solutions are shown in Fig. A1. The minimum and maximum values, as well as the standard deviation from the corresponding Gaussian distribution, are summarized in Table A2.

The standard deviation is the measure for the systematic error of the volume linear depolarization. It is slightly higher in the dust layer than in the aerosol-free Rayleigh background.

The systematic error for the particle linear depolarization ratio mainly includes the uncertainties of the volume depolarization ratio (Table A2) and the backscatter ratio (molecular backscatter coefficient divided by particle backscatter coefficient). For the particle backscatter coefficient, uncertainties of 5, 10, and $15 \%$ for 355,532 , and $1064 \mathrm{~nm}$, respectively, are assumed. Less Rayleigh signal towards higher wavelengths increases the uncertainty in the reference value for the calculation of the particle backscatter coefficient. The uncertainty of the molecular backscatter coefficient is $<1 \%$ because it is calculated from the temperature and pressure profiles of the radiosondes which were launched twice a day at the time of the measurements. The molecular depolarization is calculated from the transmission curves of the interference filters and depends on temperature (Behrendt and Nakamura, 2002). An error of $10 \%$ is assumed. 
Competing interests. The authors declare that they have no conflict of interest.

Special issue statement. This article is part of the special issue "The Saharan Aerosol Long-range Transport and Aerosol-Cloudinteraction Experiment (SALTRACE) (ACP/AMT inter-journal SI)". It does not belong to a conference.

Acknowledgements. The perfect logistic support of CIMH during the SALTRACE preparation phase and intensive field phases in 2013 and 2014 is gratefully acknowledged. We are grateful to the AERONET team for performing high-quality SALTRACE sun photometer calibrations and for providing high-quality data products. We would like to express our gratitude to the CALIPSO science team for the careful CALIOP profile data analysis. We thank the HYSPLIT team for the possibility to compute backward trajectories. We are grateful to Laurentiu Baschir and the Lidar Calibration Center (Lical), Bucharest, Romania, for good service regarding the characterization of lidar optical elements. This activity is support by ACTRIS Research Infrastructure (EU H2020-R\&I) under grant agreement no. 654169. The authors want to thank the two anonymous referees for all their time and effort that they put in carefully reading the manuscript. Their relevant comments helped to improve the quality of this publication.

Edited by: Cyrille Flamant

Reviewed by: two anonymous referees

\section{References}

AERONET: Aerosol Robotic Network aerosol data base, available at: https://aeronet.gsfc.nasa.gov/, last access: 20 December 2016.

Althausen, D., Müller, D., Ansmann, A., Wandinger, U., Hube, H., Clauder, E., and Zörner, S.: Scanning 6Wavelength 11-Channel Aerosol Lidar, J. Atmos. Ocean. Tech., 17, 1469-1482, https://doi.org/10.1175/15200426(2000)017<1469:SWCAL>2.0.CO;2, 2000.

Amiridis, V., Wandinger, U., Marinou, E., Giannakaki, E., Tsekeri, A., Basart, S., Kazadzis, S., Gkikas, A., Taylor, M., Baldasano, J., and Ansmann, A.: Optimizing CALIPSO Saharan dust retrievals, Atmos. Chem. Phys., 13, 12089-12106, https://doi.org/10.5194/acp-13-12089-2013, 2013.

Ansmann, A., Wandinger, U., Riebesell, M., Weitkamp, C., and Michaelis, W.: Independent measurement of extinction and backscatter profiles in cirrus clouds by using a combined Raman elastic-backscatter lidar, Appl. Optics, 31, 7113-7131, https://doi.org/10.1364/AO.31.007113, 1992.

Ansmann, A., Wagner, F., Müller, D., Althausen, D., Herber, A., von Hoyningen-Huene, W., and Wandinger, U.: European pollution outbreaks during ACE 2: Optical particle properties inferred from multiwavelength lidar and star-Sun photometry, J. Geophys. Res.-Atmos., 107, AAC 8-1-AAC 8-14, https://doi.org/10.1029/2001JD001109, 2002.

Ansmann, A., Bösenberg, J., Chaikovsky, A., Comerón, A., Eckhardt, S., Eixmann, R., Freudenthaler, V., Ginoux, P., Komguem, L., Linné, H., Márquez, M. A. L., Matthias, V., Mattis, I., Mitev,
V., Müller, D., Music, S., Nickovic, S., Pelon, J., Sauvage, L., Sobolewsky, P., Srivastava, M. K., Stohl, A., Torres, O., Vaughan, G., Wandinger, U., and Wiegner, M.: Long-range transport of Saharan dust to northern Europe: The 11-16 October 2001 outbreak observed with EARLINET, J. Geophys. Res.-Atmos., 108, 4783, https://doi.org/10.1029/2003JD003757, 2003.

Ansmann, A., Tesche, M., Knippertz, P., Bierwirth, E., Althausen, D., Müller, D., and Schulz, O.: Vertical profiling of convective dust plumes in southern Morocco during SAMUM, Tellus B, 61, 340-353, https://doi.org/10.1111/j.1600-0889.2008.00384.x, 2009.

Ansmann, A., Petzold, A., Kandler, K., Tegen, I., Wendisch, M., Müller, D., Weinzierl, B., Müller, T., and Heintzenberg, J.: Saharan Mineral Dust Experiments SAMUM-1 and SAMUM-2: what have we learned?, Tellus B, 63, 403-429, https://doi.org/10.1111/j.1600-0889.2011.00555.x, 2011.

Ansmann, A., Rittmeister, F., Engelmann, R., Basart, S., Benedetti, A., Spyrou, C., Skupin, A., Baars, H., Seifert, P., Senf, F., and Kanitz, T.: Profiling of Saharan dust from the Caribbean to West Africa, Part 2: Shipborne lidar measurements versus forecasts, Atmos. Chem. Phys. Discuss., https://doi.org/10.5194/acp-2017502, in review, 2017.

Baars, H., Ansmann, A., Althausen, D., Engelmann, R., Artaxo, P., Pauliquevis, T., and Souza, R.: Further evidence for significant smoke transport from Africa to Amazonia, Geophys. Res. Lett., 38, L20802, https://doi.org/10.1029/2011GL049200, 2011.

Behrendt, A. and Nakamura, T.: Calculation of the calibration constant of polarization lidar and its dependency on atmospheric temperature, Opt. Express, 10, 805-817, https://doi.org/10.1364/OE.10.000805, 2002.

Biele, J., Beyerle, G., and Baumgarten, G.: Polarization lidar: Corrections of instrumental effects, Opt. Express, 7, 427-435, https://doi.org/10.1364/OE.7.000427, 2000.

Bovchaliuk, V., Goloub, P., Podvin, T., Veselovskii, I., Tanre, D., Chaikovsky, A., Dubovik, O., Mortier, A., Lopatin, A., Korenskiy, M., and Victori, S.: Comparison of aerosol properties retrieved using GARRLiC, LIRIC, and Raman algorithms applied to multi-wavelength lidar and sun/sky-photometer data, Atmos. Meas. Tech., 9, 3391-3405, https://doi.org/10.5194/amt-9-33912016, 2016.

Bravo-Aranda, J. A., Belegante, L., Freudenthaler, V., AladosArboledas, L., Nicolae, D., Granados-Muñoz, M. J., GuerreroRascado, J. L., Amodeo, A., D’Amico, G., Engelmann, R., Pappalardo, G., Kokkalis, P., Mamouri, R., Papayannis, A., NavasGuzmán, F., Olmo, F. J., Wandinger, U., Amato, F., and Haeffelin, M.: Assessment of lidar depolarization uncertainty by means of a polarimetric lidar simulator, Atmos. Meas. Tech., 9, 49354953, https://doi.org/10.5194/amt-9-4935-2016, 2016.

Burton, S. P., Ferrare, R. A., Hostetler, C. A., Hair, J. W., Rogers, R. R., Obland, M. D., Butler, C. F., Cook, A. L., Harper, D. B., and Froyd, K. D.: Aerosol classification using airborne High Spectral Resolution Lidar measurements - methodology and examples, Atmos. Meas. Tech., 5, 73-98, https://doi.org/10.5194/amt-5-732012, 2012.

Burton, S. P., Hair, J. W., Kahnert, M., Ferrare, R. A., Hostetler, C. A., Cook, A. L., Harper, D. B., Berkoff, T. A., Seaman, S. T., Collins, J. E., Fenn, M. A., and Rogers, R. R.: Observations of the spectral dependence of linear particle depolarization ratio of aerosols using NASA Langley airborne High Spec- 
tral Resolution Lidar, Atmos. Chem. Phys., 15, 13453-13473, https://doi.org/10.5194/acp-15-13453-2015, 2015.

CALIPSO: CALIPSO/CALIOP Level 2, Lidar Aerosol Profile Data, version 3.30, https://doi.org/10.5067/CALIOP/CALIPSO/ CAL_LID_L2_05kmAPro-Prov-V3-30_L2-003.30, 2016.

Chaikovsky, A., Dubovik, O., Holben, B., Bril, A., Goloub, P., Tanré, D., Pappalardo, G., Wandinger, U., Chaikovskaya, L., Denisov, S., Grudo, J., Lopatin, A., Karol, Y., Lapyonok, T., Amiridis, V., Ansmann, A., Apituley, A., Allados-Arboledas, L., Binietoglou, I., Boselli, A., D’Amico, G., Freudenthaler, V., Giles, D., Granados-Muñoz, M. J., Kokkalis, P., Nicolae, D., Oshchepkov, S., Papayannis, A., Perrone, M. R., Pietruczuk, A., Rocadenbosch, F., Sicard, M., Slutsker, I., Talianu, C., De Tomasi, F., Tsekeri, A., Wagner, J., and Wang, X.: Lidar-Radiometer Inversion Code (LIRIC) for the retrieval of vertical aerosol properties from combined lidar/radiometer data: development and distribution in EARLINET, Atmos. Meas. Tech., 9, 1181-1205, https://doi.org/10.5194/amt-9-1181-2016, 2016.

Chouza, F., Reitebuch, O., Groß, S., Rahm, S., Freudenthaler, V., Toledano, C., and Weinzierl, B.: Retrieval of aerosol backscatter and extinction from airborne coherent Doppler wind lidar measurements, Atmos. Meas. Tech., 8, 2909-2926, https://doi.org/10.5194/amt-8-2909-2015, 2015.

Chouza, F., Reitebuch, O., Benedetti, A., and Weinzierl, B.: Saharan dust long-range transport across the Atlantic studied by an airborne Doppler wind lidar and the MACC model, Atmos. Chem. Phys., 16, 11581-11600, https://doi.org/10.5194/acp-16-115812016, 2016a.

Chouza, F., Reitebuch, O., Jähn, M., Rahm, S., and Weinzierl, B.: Vertical wind retrieved by airborne lidar and analysis of island induced gravity waves in combination with numerical models and in situ particle measurements, Atmos. Chem. Phys., 16, 46754692, https://doi.org/10.5194/acp-16-4675-2016, 2016 b.

Colarco, P. R., Toon, O. B., Reid, J. S., Livingston, J. M., Russell, P. B., Redemann, J., Schmid, B., Maring, H. B., Savoie, D., Welton, E. J., Campbell, J. R., Holben, B. N., and Levy, R.: Saharan dust transport to the Caribbean during PRIDE: 2. Transport, vertical profiles, and deposition in simulations of in situ and remote sensing observations, J. Geophys. Res.-Atmos., 108, 8590, https://doi.org/10.1029/2002JD002659, 2003.

Curtis, D. B., Meland, B., Aycibin, M., Arnold, N. P., Grassian, V. H., Young, M. A., and Kleiber, P. D.: A laboratory investigation of light scattering from representative components of mineral dust aerosol at a wavelength of $550 \mathrm{~nm}$, J. Geophys. Res.Atmos., 113, D08210, https://doi.org/10.1029/2007JD009387, 2008.

David, G., Thomas, B., Nousiainen, T., Miffre, A., and Rairoux, P.: Retrieving simulated volcanic, desert dust and sea-salt particle properties from two/three-component particle mixtures using UV-VIS polarization lidar and T matrix, Atmos. Chem. Phys., 13, 6757-6776, https://doi.org/10.5194/acp-136757-2013, 2013.

Dawson, K. W., Meskhidze, N., Josset, D., and Gassó, S.: Spaceborne observations of the lidar ratio of marine aerosols, Atmos. Chem. Phys., 15, 3241-3255, https://doi.org/10.5194/acp15-3241-2015, 2015.

di Sarra, A., Di Iorio, T., Cacciani, M., Fiocco, G., and Fuà, D.: Saharan dust profiles measured by lidar at
Lampedusa, J. Geophys. Res.-Atmos., 106, 10335-10347, https://doi.org/10.1029/2000JD900734, 2001.

Dubovik, O., Sinyuk, A., Lapyonok, T., Holben, B. N., Mishchenko, M., Yang, P., Eck, T. F., Volten, H., Muñoz, O., Veihelmann, B., van der Zande, W. J., Leon, J.-F., Sorokin, M., and Slutsker, I.: Application of spheroid models to account for aerosol particle nonsphericity in remote sensing of desert dust, J. Geophys. Res.Atmos., 111, D11208, https://doi.org/10.1029/2005JD006619, 2006.

Engelmann, R., Kanitz, T., Baars, H., Heese, B., Althausen, D., Skupin, A., Wandinger, U., Komppula, M., Stachlewska, I. S., Amiridis, V., Marinou, E., Mattis, I., Linné, H., and Ansmann, A.: The automated multiwavelength Raman polarization and water-vapor lidar Polly XT: the neXT generation, Atmos. Meas. Tech., 9, 1767-1784, https://doi.org/10.5194/amt-9-1767-2016, 2016.

Flamant, C., Trouillet, V., Chazette, P., and Pelon, J.: Wind speed dependence of atmospheric boundary layer optical properties and ocean surface reflectance as observed by airborne backscatter lidar, J. Geophys. Res.-Oceans, 103, 25137-25158, https://doi.org/10.1029/98JC02284, 1998.

Franke, K., Ansmann, A., Müller, D., Althausen, D., Venkataraman, C., Reddy, M. S., Wagner, F., and Scheele, R.: Optical properties of the Indo-Asian haze layer over the tropical Indian Ocean, J. Geophys. Res.-Atmos., 108, 4059, https://doi.org/10.1029/2002JD002473, 2003.

Freudenthaler, V.: The telecover test: A quality assurance tool for the optical part of a lidar system, in: 24th International Laser Radar Conference, 23-27 June 2008, Boulder, CO, USA, S01P3, 2008.

Freudenthaler, V.: About the effects of polarising optics on lidar signals and the $\Delta 90$ calibration, Atmos. Meas. Tech., 9, 41814255, https://doi.org/10.5194/amt-9-4181-2016, 2016.

Freudenthaler, V., Esselborn, M., Wiegner, M., Heese, B., Tesche, M., Ansmann, A., Müller, D., Althausen, D., Wirth, M., Fix, A., Ehret, G., Knippertz, P., Toledano, C., Gasteiger, J., Garhammer, M., and Seefeldner, M.: Depolarization ratio profiling at several wavelengths in pure Saharan dust during SAMUM 2006, Tellus B, 61, 165-179, https://doi.org/10.1111/j.16000889.2008.00396.x, 2009.

Freudenthaler, V., Seefeldner, M., Groß, S., and Wandinger, U.: Accuracy of Linear Depolarisation Ratios in Clean Air Ranges Measured with POLIS-6 at 355 and 532 NM, EPJ Web of Conferences, 119, 25013, https://doi.org/10.1051/epjconf/201611925013, 2016.

Garimella, S., Huang, Y.-W., Seewald, J. S., and Cziczo, D. J.: Cloud condensation nucleus activity comparison of dryand wet-generated mineral dust aerosol: the significance of soluble material, Atmos. Chem. Phys., 14, 6003-6019, https://doi.org/10.5194/acp-14-6003-2014, 2014.

Gasteiger, J. and Freudenthaler, V.: Benefit of depolarization ratio at $\lambda=1064 \mathrm{~nm}$ for the retrieval of the aerosol microphysics from lidar measurements, Atmos. Meas. Tech., 7, 3773-3781, https://doi.org/10.5194/amt-7-3773-2014, 2014.

Gasteiger, J., Wiegner, M., Groß, S., Freudenthaler, V., Toledano, C., Tesche, M., and Kandler, K.: Modelling lidar-relevant optical properties of complex mineral dust aerosols, Tellus B, 63, 725741, https://doi.org/10.1111/j.1600-0889.2011.00559.x, 2011. 
Gasteiger, J., Groß, S., Sauer, D., Haarig, M., Ansmann, A., and Weinzierl, B.: Particle settling and vertical mixing in the Saharan Air Layer as seen from an integrated model, lidar, and in situ perspective, Atmos. Chem. Phys., 17, 297-311, https://doi.org/10.5194/acp-17-297-2017, 2017.

Gimmestad, G. G.: Reexamination of depolarization in lidar measurements, Appl. Optics, 47, 3795-3802, https://doi.org/10.1364/AO.47.003795, 2008.

Gobbi, G. P.: Polarization lidar returns from aerosols and thin clouds: a framework for the analysis, Appl. Optics, 37, 55055508, https://doi.org/10.1364/AO.37.005505,1998.

Gobbi, G. P., Barnaba, F., Giorgi, R., and Santacasa, A.: Altitude-resolved properties of a Saharan dust event over the Mediterranean, Atmos. Environ., 34, 5119-5127, https://doi.org/10.1016/S1352-2310(00)00194-1, 2000.

Groß, S., Gasteiger, J., Freudenthaler, V., Wiegner, M., Geiß, A., Schladitz, A., Toledano, C., Kandler, K., Tesche, M., Ansmann, A., and Wiedensohler, A.: Characterization of the planetary boundary layer during SAMUM-2 by means of lidar measurements, Tellus B, 63, 695-705, https://doi.org/10.1111/j.16000889.2011.00557.x, 2011a.

Groß, S., Tesche, M., Freudenthaler, V., Toledano, C., Wiegner, M., Ansmann, A., Althausen, D., and Seefeldner, M.: Characterization of Saharan dust, marine aerosols and mixtures of biomassburning aerosols and dust by means of multi-wavelength depolarization and Raman lidar measurements during SAMUM 2, Tellus B, 63, 706-724, https://doi.org/10.1111/j.16000889.2011.00556.x, 2011b.

Groß, S., Freudenthaler, V., Schepanski, K., Toledano, C., Schäfler, A., Ansmann, A., and Weinzierl, B.: Optical properties of long-range transported Saharan dust over Barbados as measured by dual-wavelength depolarization Raman lidar measurements, Atmos. Chem. Phys., 15, 11067-11080, https://doi.org/10.5194/acp-15-11067-2015, 2015.

Groß, S., Gasteiger, J., Freudenthaler, V., Müller, T., Sauer, D., Toledano, C., and Ansmann, A.: Saharan dust contribution to the Caribbean summertime boundary layer - a lidar study during SALTRACE, Atmos. Chem. Phys., 16, 11535-11546, https://doi.org/10.5194/acp-16-11535-2016, 2016.

Haarig, M., Althausen, D., Ansmann, A., Klepel, A., Baars, H., Engelmann, R., Groß, S., and Freudenthaler, V.: Measurement of the Linear Depolarization Ratio of Aged Dust at Three Wavelengths (355, 532 and $1064 \mathrm{~nm}$ ) Simultaneously over Barbados, EPJ Web of Conferences, 119, 18009, https://doi.org/10.1051/epjconf/201611918009, 2016 a.

Haarig, M., Engelmann, R., Ansmann, A., Veselovskii, I., Whiteman, D. N., and Althausen, D.: $1064 \mathrm{~nm}$ rotational Raman lidar for particle extinction and lidar-ratio profiling: cirrus case study, Atmos. Meas. Tech., 9, 4269-4278, https://doi.org/10.5194/amt9-4269-2016, 2016b

Haarig, M., Ansmann, A., Gasteiger, J., Kandler, K., Althausen, D., Baars, H., and Farrell, D. A.: Dry versus wet marine particle optical properties: RH dependence of depolarization ratio, backscatter and extinction from multiwavelength lidar measurements during SALTRACE, Atmos. Chem. Phys. Discuss., https://doi.org/10.5194/acp-2017-545, in review, 2017.

Haywood, J. M., Pelon, J., Formenti, P., Bharmal, N., Brooks, M., Capes, G., Chazette, P., Chou, C., Christopher, S., Coe, H., Cuesta, J., Derimian, Y., Desboeufs, K., Greed, G., Harrison,
M., Heese, B., Highwood, E. J., Johnson, B., Mallet, M., Marticorena, B., Marsham, J., Milton, S., Myhre, G., Osborne, S. R., Parker, D. J., Rajot, J.-L., Schulz, M., Slingo, A., Tanré, D., and Tulet, P.: Overview of the Dust and Biomass-burning Experiment and African Monsoon Multidisciplinary Analysis Special Observing Period-0, J. Geophys. Res.-Atmos., 113, D00C17, https://doi.org/10.1029/2008JD010077, 2008.

Heinold, B., Tegen, I., Schepanski, K., Tesche, M., Esselborn, M., Freudenthaler, V., Groß, S., Kandler, K., Knippertz, P., Müeller, D., Schladitz, A., Toledano, C., Weinzierl, B., Ansmann, A., Althausen, D., Müller, T., Petzold, A., and Wiedensohler, A.: Regional modelling of Saharan dust and biomass-burning smoke, Tellus B, 63, 781-799, https://doi.org/10.1111/j.16000889.2011.00570.x, 2011.

Heintzenberg, J.: The SAMUM-1 experiment over Southern Morocco: overview and introduction, Tellus B, 61, 2-11, https://doi.org/10.1111/j.1600-0889.2008.00403.x, 2009.

Hofer, J., Althausen, D., Abdullaev, S. F., Makhmudov, A. N., Nazarov, B. I., Schettler, G., Engelmann, R., Baars, H., Fomba, K. W., Müller, K., Heinold, B., Kandler, K., and Ansmann, A. Long-term profiling of mineral dust and pollution aerosol with multiwavelength polarization/Raman lidar at the Central Asian site of Dushanbe, Tajikistan: Case studies, Atmos. Chem. Phys. Discuss., https://doi.org/10.5194/acp-2017-559, in review, 2017.

Holben, B., Eck, T., Slutsker, I., Tanré, D., Buis, J., Setzer, A., Vermote, E., Reagan, J., Kaufman, Y., Nakajima, T., Lavenu, F., Jankowiak, I., and Smirnov, A.: AERONET - A Federated Instrument Network and Data Archive for Aerosol Characterization, Remote Sens. Environ., 66, 1-16, https://doi.org/10.1016/S0034-4257(98)00031-5, 1998.

Huebert, B. J., Bates, T., Russell, P. B., Shi, G., Kim, Y. J., Kawamura, K., Carmichael, G., and Nakajima, T.: An overview of ACE-Asia: Strategies for quantifying the relationships between Asian aerosols and their climatic impacts, J. Geophys. Res.-Atmos., 108, 8633, https://doi.org/10.1029/2003JD003550, 2003.

Huneeus, N., Schulz, M., Balkanski, Y., Griesfeller, J., Prospero, J., Kinne, S., Bauer, S., Boucher, O., Chin, M., Dentener, F., Diehl, T., Easter, R., Fillmore, D., Ghan, S., Ginoux, P., Grini, A., Horowitz, L., Koch, D., Krol, M. C., Landing, W., Liu, X., Mahowald, N., Miller, R., Morcrette, J.-J., Myhre, G., Penner, J., Perlwitz, J., Stier, P., Takemura, T., and Zender, C. S.: Global dust model intercomparison in AeroCom phase I, Atmos. Chem. Phys., 11, 7781-7816, https://doi.org/10.5194/acp11-7781-2011, 2011.

HYSPLIT: HYbrid Single-Particle Lagrangian Integrated Trajectory model, backward trajectory calculation tool, http://ready.arl. noaa.gov/HYSPLIT.php, last access: 20 December 2016.

Iwasaka, Y., Yamato, M., Imasu, R., and Ono, A.: Transport of Asian dust (KOSA) particles; importance of weak KOSA events on the geochemical cycle of soil particles, Tellus B, 40B, 494503, https://doi.org/10.1111/j.1600-0889.1988.tb00119.x, 1988.

Jähn, M., Muñoz-Esparza, D., Chouza, F., Reitebuch, O., Knoth, O., Haarig, M., and Ansmann, A.: Investigations of boundary layer structure, cloud characteristics and vertical mixing of aerosols at Barbados with large eddy simulations, Atmos. Chem. Phys., 16, 651-674, https://doi.org/10.5194/acp-16-651-2016, 2016.

Järvinen, E., Kemppinen, O., Nousiainen, T., Kociok, T., Möhler, O., Leisner, T., and Schnaiter, M.: Laboratory in- 
vestigations of mineral dust near-backscattering depolarization ratios, J. Quant. Spectrosc. Ra., 178, 192-208, https://doi.org/10.1016/j.jqsrt.2016.02.003, 2016.

Johnson, B. T. and Osborne, S. R.: Physical and optical properties of mineral dust aerosol measured by aircraft during the GERBILS campaign, Q. J. Roy. Meteor. Soc., 137, 1117-1130, https://doi.org/10.1002/qj.777, 2011.

Jung, E., Albrecht, B., Prospero, J. M., Jonsson, H. H., and Kreidenweis, S. M.: Vertical structure of aerosols, temperature, and moisture associated with an intense African dust event observed over the eastern Caribbean, J. Geophys. Res.-Atmos., 118, 46234643, https://doi.org/10.1002/jgrd.50352, 2013.

Kanitz, T., Ansmann, A., Engelmann, R., and Althausen, D.: Northsouth cross sections of the vertical aerosol distribution over the Atlantic Ocean from multiwavelength Raman/polarization lidar during Polarstern cruises, J. Geophys. Res.-Atmos., 118, 26432655, https://doi.org/10.1002/jgrd.50273, 2013.

Kanitz, T., Engelmann, R., Heinold, B., Baars, H., Skupin, A., and Ansmann, A.: Tracking the Saharan Air Layer with shipborne lidar across the tropical Atlantic, Geophys. Res. Lett., 41, 10441050, https://doi.org/10.1002/2013GL058780, 2014.

Karyampudi, V. M., Palm, S. P., Reagen, J. A., Fang, H., Grant, W. B., Hoff, R. M., Moulin, C., Pierce, H. F., Torres, O., Browell, E. V., and Melfi, S. H.: Validation of the Saharan Dust Plume Conceptual Model Using Lidar, Meteosat, and ECMWF Data, B. Am. Meteorol. Soc., 80, 1045-1075, https://doi.org/10.1175/15200477(1999)080<1045:VOTSDP>2.0.CO;2,1999.

Kemppinen, O., Nousiainen, T., and Lindqvist, H.: The impact of surface roughness on scattering by realistically shaped wavelength-scale dust particles, J. Quant. Spectrosc. Ra., 150, 55-67, https://doi.org/10.1016/j.jqsrt.2014.05.024, 2015a.

Kemppinen, O., Nousiainen, T., Merikallio, S., and Räisänen, P.: Retrieving microphysical properties of dust-like particles using ellipsoids: the case of refractive index, Atmos. Chem. Phys., 15, 11117-11132, https://doi.org/10.5194/acp-15-11117-2015, $2015 b$.

Kobayashi, A., Hayashida, S., Okada, K., and Iwasaka, Y.: Measurements of the Polarization Properties of Kosa (Asian Dust-storm) Particles by a Laser Radar in Spring 1983, J. Meteorol. Soc. Jpn. Ser. II, 63, 144-149, https://doi.org/10.2151/jmsj1965.63.1_144, 1985.

Kristensen, T. B., Müller, T., Kandler, K., Benker, N., Hartmann, M., Prospero, J. M., Wiedensohler, A., and Stratmann, F.: Properties of cloud condensation nuclei $(\mathrm{CCN})$ in the trade wind marine boundary layer of the western North Atlantic, Atmos. Chem. Phys., 16, 2675-2688, https://doi.org/10.5194/acp-162675-2016, 2016.

Lindqvist, H., Jokinen, O., Kandler, K., Scheuvens, D., and Nousiainen, T.: Single scattering by realistic, inhomogeneous mineral dust particles with stereogrammetric shapes, Atmos. Chem. Phys., 14, 143-157, https://doi.org/10.5194/acp-14-143-2014, 2014.

Liu, L., Mishchenko, M. I., Hovenier, J. W., Volten, H., and Muñoz, O.: Scattering matrix of quartz aerosols: comparison and synthesis of laboratory and Lorenz-Mie results, J. Quant. Spectrosc. Ra., 79, 911-920, https://doi.org/10.1016/S00224073(02)00328-X, 2003.
Lopatin, A., Dubovik, O., Chaikovsky, A., Goloub, P., Lapyonok, T., Tanré, D., and Litvinov, P.: Enhancement of aerosol characterization using synergy of lidar and sun-photometer coincident observations: the GARRLiC algorithm, Atmos. Meas. Tech., 6, 2065-2088, https://doi.org/10.5194/amt-6-2065-2013, 2013.

Mamouri, R. E. and Ansmann, A.: Fine and coarse dust separation with polarization lidar, Atmos. Meas. Tech., 7, 3717-3735, https://doi.org/10.5194/amt-7-3717-2014, 2014.

Mamouri, R.-E. and Ansmann, A.: Potential of polarization/Raman lidar to separate fine dust, coarse dust, maritime, and anthropogenic aerosol profiles, Atmos. Meas. Tech. Discuss., https://doi.org/10.5194/amt-2017-131, in review, 2017.

Marinou, E., Amiridis, V., Binietoglou, I., Tsikerdekis, A., Solomos, S., Proestakis, E., Konsta, D., Papagiannopoulos, N., Tsekeri, A., Vlastou, G., Zanis, P., Balis, D., Wandinger, U., and Ansmann, A.: Three-dimensional evolution of Saharan dust transport towards Europe based on a 9-year EARLINEToptimized CALIPSO dataset, Atmos. Chem. Phys., 17, 58935919, https://doi.org/10.5194/acp-17-5893-2017, 2017.

Mattis, I., Ansmann, A., Müller, D., Wandinger, U., and Althausen, D.: Dual-wavelength Raman lidar observations of the extinctionto-backscatter ratio of Saharan dust, Geophys. Res. Lett., 29, 201-20-4, https://doi.org/10.1029/2002GL014721, 2002.

Mattis, I., Tesche, M., Grein, M., Freudenthaler, V., and Müller, D.: Systematic error of lidar profiles caused by a polarization-dependent receiver transmission: quantification and error correction scheme, Appl. Optics, 48, 2742-2751, https://doi.org/10.1364/AO.48.002742, 2009.

McConnell, C. L., Highwood, E. J., Coe, H., Formenti, P., Anderson, B., Osborne, S., Nava, S., Desboeufs, K., Chen, G., and Harrison, M. A. J.: Seasonal variations of the physical and optical characteristics of Saharan dust: Results from the Dust Outflow and Deposition to the Ocean (DODO) experiment, J. Geophys. Res.-Atmos., 113, D14S05, https://doi.org/10.1029/2007JD009606, 2008.

McNeil, W. R. and Carsweil, A. L.: Lidar polarization studies of the troposphere, Appl. Optics, 14, 2158-2168, https://doi.org/10.1364/AO.14.002158, 1975.

Miffre, A., Mehri, T., Francis, M., and Rairoux, P.: UV-VIS depolarization from Arizona Test Dust particles at exact backscattering angle, J. Quant. Spectrosc. Ra., 169, 79-90, https://doi.org/10.1016/j.jqsrt.2015.09.016, 2016.

Müller, D., Ansmann, A., Freudenthaler, V., Kandler, K., Toledano, C., Hiebsch, A., Gasteiger, J., Esselborn, M., Tesche, M., Heese, B., Althausen, D., Weinzierl, B., Petzold, A., and von Hoyningen-Huene, W.: Mineral dust observed with AERONET Sun photometer, Raman lidar, and in situ instruments during SAMUM 2006: Shape-dependent particle properties, J. Geophys. Res.-Atmos., 115, D11207, https://doi.org/10.1029/2009JD012523, 2010a.

Müller, D., Weinzierl, B., Petzold, A., Kandler, K., Ansmann, A., Müller, T., Tesche, M., Freudenthaler, V., Esselborn, M., Heese, B., Althausen, D., Schladitz, A., Otto, S., and Knippertz, P.: Mineral dust observed with AERONET Sun photometer, Raman lidar, and in situ instruments during SAMUM 2006: Shapeindependent particle properties, J. Geophys. Res.-Atmos., 115, D07202, https://doi.org/10.1029/2009JD012520, 2010b.

Müller, D., Lee, K.-H., Gasteiger, J., Tesche, M., Weinzierl, B., Kandler, K., Müller, T., Toledano, C., Otto, S., Althausen, D., and 
Ansmann, A.: Comparison of optical and microphysical properties of pure Saharan mineral dust observed with AERONET Sun photometer, Raman lidar, and in situ instruments during SAMUM 2006, J. Geophys. Res.-Atmos., 117, D07211, https://doi.org/10.1029/2011JD016825, 2012.

Müller, D., Veselovskii, I., Kolgotin, A., Tesche, M., Ansmann, A., and Dubovik, O.: Vertical profiles of pure dust and mixed smoke-dust plumes inferred from inversion of multiwavelength Raman/polarization lidar data and comparison to AERONET retrievals and in situ observations, Appl. Optics, 52, 3178-3202, https://doi.org/10.1364/AO.52.003178, 2013.

Murayama, T., Sugimoto, N., Uno, I., Kinoshita, K., Aoki, K., Hagiwara, N., Liu, Z., Matsui, I., Sakai, T., Shibata, T., Arao, K., Sohn, B.-J., Won, J.-G., Yoon, S.-C., Li, T., Zhou, J., Hu, H., Abo, M., Iokibe, K., Koga, R., and Iwasaka, Y.: Groundbased network observation of Asian dust events of April 1998 in east Asia, J. Geophys. Res.-Atmos., 106, 18345-18359, https://doi.org/10.1029/2000JD900554, 2001.

Omar, A. H., Winker, D. M., Vaughan, M. A., Hu, Y., Trepte, C. R., Ferrare, R. A., Lee, K.-P., Hostetler, C. A., Kittaka, C., Rogers, R. R., Kuehn, R. E., and Liu, Z.: The CALIPSO Automated Aerosol Classification and Lidar Ratio Selection Algorithm, J. Atmos. Ocean. Tech., 26, 1994-2014, https://doi.org/10.1175/2009JTECHA1231.1, 2009.

Papayannis, A., Balis, D., Amiridis, V., Chourdakis, G., Tsaknakis, G., Zerefos, C., Castanho, A. D. A., Nickovic, S., Kazadzis, S., and Grabowski, J.: Measurements of Saharan dust aerosols over the Eastern Mediterranean using elastic backscatter-Raman lidar, spectrophotometric and satellite observations in the frame of the EARLINET project, Atmos. Chem. Phys., 5, 2065-2079, https://doi.org/10.5194/acp-5-2065-2005, 2005.

Preißler, J., Wagner, F., Pereira, S. N., and Guerrero-Rascado, J. L.: Multi-instrumental observation of an exceptionally strong Saharan dust outbreak over Portugal, J. Geophys. Res.-Atmos., 116, D24204, https://doi.org/10.1029/2011JD016527, 2011.

Reid, J. S., Kinney, J. E., Westphal, D. L., Holben, B. N., Welton, E. J., Tsay, S.-C., Eleuterio, D. P., Campbell, J. R., Christopher, S. A., Colarco, P. R., Jonsson, H. H., Livingston, J. M., Maring, H. B., Meier, M. L., Pilewskie, P., Prospero, J. M., Reid, E. A., Remer, L. A., Russell, P. B., Savoie, D. L., Smirnov, A., and Tanré, D.: Analysis of measurements of Saharan dust by airborne and ground-based remote sensing methods during the Puerto Rico Dust Experiment (PRIDE), J. Geophys. Res.-Atmos., 108, 8586, https://doi.org/10.1029/2002JD002493, 2003.

Rittmeister, F., Ansmann, A., Engelmann, R., Skupin, A., Baars, H., Kanitz, T., and Kinne, S.: From the Caribbean to West Africa: Four weeks of continuous dust and marine aerosol profiling with shipborne polarization/Raman lidar - a contribution to SALTRACE, Atmos. Chem. Phys. Discuss., https://doi.org/10.5194/acp-2017-130, in review, 2017.

Ryder, C. L., Highwood, E. J., Rosenberg, P. D., Trembath, J., Brooke, J. K., Bart, M., Dean, A., Crosier, J., Dorsey, J., Brindley, H., Banks, J., Marsham, J. H., McQuaid, J. B., Sodemann, H., and Washington, R.: Optical properties of Saharan dust aerosol and contribution from the coarse mode as measured during the Fennec 2011 aircraft campaign, Atmos. Chem. Phys., 13, 303325, https://doi.org/10.5194/acp-13-303-2013, 2013.

Sakai, T., Nagai, T., Zaizen, Y., and Mano, Y.: Backscattering linear depolarization ratio measurements of min- eral, sea-salt, and ammonium sulfate particles simulated in a laboratory chamber, Appl. Optics, 49, 4441-4449, https://doi.org/10.1364/AO.49.004441, 2010.

Shimizu, A., Sugimoto, N., Matsui, I., Arao, K., Uno, I., Murayama, T., Kagawa, N., Aoki, K., Uchiyama, A., and Yamazaki, A.: Continuous observations of Asian dust and other aerosols by polarization lidars in China and Japan during ACE-Asia, J. Geophys. Res.-Atmos., 109, D19S17, https://doi.org/10.1029/2002JD003253, 2004.

Solomos, S., Ansmann, A., Mamouri, R.-E., Binietoglou, I., Patlakas, P., Marinou, E., and Amiridis, V.: Remote sensing and modelling analysis of the extreme dust storm hitting the Middle East and eastern Mediterranean in September 2015, Atmos. Chem. Phys., 17, 4063-4079, https://doi.org/10.5194/acp17-4063-2017, 2017.

Stein, A. F., Draxler, R. R., Rolph, G. D., Stunder, B. J. B., Cohen, M. D., and Ngan, F.: NOAA's HYSPLIT Atmospheric Transport and Dispersion Modeling System, B. Am. Meteorol. Soc., 96, 2059-2077, https://doi.org/10.1175/BAMS-D-14$00110.1,2015$.

Stevens, B., Farrell, D., Hirsch, L., Jansen, F., Nuijens, L., Serikov, I., Brügmann, B., Forde, M., Linne, H., Lonitz, K., and Prospero, J. M.: The Barbados Cloud Observatory: Anchoring Investigations of Clouds and Circulation on the Edge of the ITCZ, B. Am. Meteorol. Soc., 97, 787-801, https://doi.org/10.1175/BAMS-D14-00247.1, 2016.

Sugimoto, N. and Lee, C. H.: Characteristics of dust aerosols inferred from lidar depolarization measurements at two wavelengths, Appl. Optics, 45, 7468-7474, https://doi.org/10.1364/AO.45.007468, 2006.

Tanré, D., Haywood, J., Pelon, J., Léon, J. F., Chatenet, B., Formenti, P., Francis, P., Goloub, P., Highwood, E. J., and Myhre, G.: Measurement and modeling of the Saharan dust radiative impact: Overview of the Saharan Dust Experiment (SHADE), J. Geophys. Res.-Atmos., 108, 8574, https://doi.org/10.1029/2002JD003273, 2003.

Tesche, M., Ansmann, A., Müller, D., Althausen, D., Mattis, I., Heese, B., Freudenthaler, V., Wiegner, M., Esselborn, M., Pisani, G., and Knippertz, P.: Vertical profiling of Saharan dust with Raman lidars and airborne HSRL in southern Morocco during SAMUM, Tellus B, 61, 144-164, https://doi.org/10.1111/j.16000889.2008.00390.x, 2009.

Tesche, M., Gross, S., Ansmann, A., Müller, D. D., Althausen, D., Freudenthaler, V., and Esselborn, M.: Profiling of Saharan dust and biomass-burning smoke with multiwavelength polarization Raman lidar at Cape Verde, Tellus B, 63, 649-676, https://doi.org/10.1111/j.1600-0889.2011.00548.x, 2011a.

Tesche, M., Müller, D., Gross, S., Ansmann, A., Althausen, D., Freudenthaler, V., Weinzierl, B., Veira, A., and Petzold, A.: Optical and microphysical properties of smoke over Cape Verde inferred from multiwavelength lidar measurements, Tellus B, 63, 677-694, https://doi.org/10.1111/j.1600-0889.2011.00549.x, $2011 \mathrm{~b}$.

Tesche, M., Wandinger, U., Ansmann, A., Althausen, D., Müller, D., and Omar, A. H.: Ground-based validation of CALIPSO observations of dust and smoke in the Cape Verde region, J. Geophys. Res.-Atmos., 118, 2889-2902, https://doi.org/10.1002/jgrd.50248, 2013. 
Toledano, C., Wiegner, M., Garhammer, M., Seefeldner, M., Gasteiger, J., Müeller, D., and Koepke, P.: Spectral aerosol optical depth characterization of desert dust during SAMUM 2006, Tellus B, 61, 216-228, https://doi.org/10.1111/j.16000889.2008.00382.x, 2009.

Toledano, C., Wiegner, M., Groß, S., Freudenthaler, V., Gasteiger, J., Müeller, D., Müeller, T., Schladitz, A., Weinzierl, B., Torres, B., and O'Neill, N. T.: Optical properties of aerosol mixtures derived from sun-sky radiometry during SAMUM-2, Tellus B, 63, 635-648, https://doi.org/10.1111/j.1600-0889.2011.00573.x, 2011.

Veselovskii, I., Dubovik, O., Kolgotin, A., Lapyonok, T., Di Girolamo, P., Summa, D., Whiteman, D. N., Mishchenko, M., and Tanré, D.: Application of randomly oriented spheroids for retrieval of dust particle parameters from multiwavelength lidar measurements, J. Geophys. Res.-Atmos., 115, D21203, https://doi.org/10.1029/2010JD014139, 2010.

Veselovskii, I., Goloub, P., Podvin, T., Bovchaliuk, V., Derimian, Y., Augustin, P., Fourmentin, M., Tanre, D., Korenskiy, M., Whiteman, D. N., Diallo, A., Ndiaye, T., Kolgotin, A., and Dubovik, O.: Retrieval of optical and physical properties of African dust from multiwavelength Raman lidar measurements during the SHADOW campaign in Senegal, Atmos. Chem. Phys., 16, 70137028, https://doi.org/10.5194/acp-16-7013-2016, 2016.

Volten, H., Muñoz, O., Rol, E., de Haan, J. F., Vassen, W., Hovenier, J. W., Muinonen, K., and Nousiainen, T.: Scattering matrices of mineral aerosol particles at $441.6 \mathrm{~nm}$ and $632.8 \mathrm{~nm}$, J. Geophys. Res.-Atmos., 106, 17375-17401, https://doi.org/10.1029/2001JD900068, 2001.

Wagner, J., Ansmann, A., Wandinger, U., Seifert, P., Schwarz, A., Tesche, M., Chaikovsky, A., and Dubovik, O.: Evaluation of the Lidar/Radiometer Inversion Code (LIRIC) to determine microphysical properties of volcanic and desert dust, Atmos. Meas. Tech., 6, 1707-1724, https://doi.org/10.5194/amt-6-1707-2013, 2013.

Wandinger, U. and Ansmann, A.: Experimental Determination of the Lidar Overlap Profile with Raman Lidar, Appl. Optics, 41, 511-514, https://doi.org/10.1364/AO.41.000511, 2002.
Wandinger, U., Müller, D., Böckmann, C., Althausen, D., Matthias, V., Bösenberg, J., Weiß, V., Fiebig, M., Wendisch, M., Stohl, A., and Ansmann, A.: Optical and microphysical characterization of biomass- burning and industrial-pollution aerosols frommultiwavelength lidar and aircraft measurements, J. Geophys. Res.-Atmos., 107, 8125, https://doi.org/10.1029/2000JD000202, 2002.

Weinzierl, B., Ansmann, A., Prospero, J. M., Althausen, D., Benker, N., Chouza, F., Dollner, M., Farrell, D., Fomba, W. K., Freudenthaler, V., Gasteiger, J., Groß, S., Haarig, M., Heinold, B., Kandler, K., Kristensen, T. B., Mayol-Bracero, O. L., Müller, T., Reitebuch, O., Sauer, D., Schäfler, A., Schepanski, K., Spanu, A., Tegen, I., Toledano, C., and Walser, A.: The Saharan Aerosol Long-range Transport and Aerosol-Cloud-Interaction Experiment (SALTRACE): overview and selected highlights, B. Am. Meteorol. Soc., 98, 1427-1451, https://doi.org/10.1175/BAMSD-15-00142.1, 2017.

West, R. A., Doose, L. R., Eibl, A. M., Tomasko, M. G., and Mishchenko, M. I.: Laboratory measurements of mineral dust scattering phase function and linear polarization, J. Geophys. Res.-Atmos., 102, 16871-16881, https://doi.org/10.1029/96JD02584, 1997.

Wex, H., Dieckmann, K., Roberts, G. C., Conrath, T., Izaguirre, M. A., Hartmann, S., Herenz, P., Schäfer, M., Ditas, F., Schmeissner, T., Henning, S., Wehner, B., Siebert, H., and Stratmann, F.: Aerosol arriving on the Caribbean island of Barbados: physical properties and origin, Atmos. Chem. Phys., 16, 14107-14130, https://doi.org/10.5194/acp-16-14107-2016, 2016.

Wiegner, M., Gasteiger, J., Kandler, K., Weinzierl, B., Rasp, K., Esselborn, M., Freudenthaler, V., Heese, B., Toledano, C., Tesche, M., and Althausen, D.: Numerical simulations of optical properties of Saharan dust aerosols with emphasis on lidar applications, Tellus B, 61, 180-194, https://doi.org/10.1111/j.16000889.2008.00381.x, 2009. 